\title{
A Proposed Mechanism of Hot-Cracking Formation During Welding Fan-Shaped Test Specimen Using Pulsed-Current Gas Tungsten Arc Welding Process
}

\author{
Mohamed Abu-Aesh ${ }^{1, ~ *}$, Mohamed Taha ${ }^{2}$, Ahmed Salem El-Sabbagh ${ }^{2}$, Lutz Dorn $^{3}$ \\ ${ }^{1}$ Mechanical Engineering Department, University of Bahrain, Manama, Kingdom of Bahrain \\ ${ }^{2}$ Design and Production Engineering Department, Ain-Shams University, Cairo, Egypt \\ ${ }^{3}$ Department of Forging and Welding Techniques, Technical University, Berlin, Germany
}

Email address:

dr_abu_aesh2@yahoo.co.uk (M. Abu-Aesh)

${ }^{*}$ Corresponding author

\section{To cite this article:}

Mohamed Abu-Aesh, Mohamed Taha, Ahmed Salem El-Sabbagh, Lutz Dorn. A Proposed Mechanism of Hot-Cracking Formation During Welding Fan-Shaped Test Specimen Using Pulsed-Current Gas Tungsten Arc Welding Process. Engineering and Applied Sciences. Vol. 6, No. 5, 2021, pp. 86-104. doi: 10.11648/j.eas.20210605.12

Received: August 21, 2021; Accepted: September 8, 2021; Published: September 15, 2021

\begin{abstract}
Solidification cracking is a significant problem during the welding of fully austenitic stainless steels. The present work is considered as the first trial to investigate and propose a mechanism of hot cracking formation when welding the Fanshaped cracking test specimen, using the pulsed current gas tungsten arc welding process (PCGTAW). The specimen lateral expansions perpendicular to welding line due to thermal effects, plus the transverse expansion due to crack opening are sensed and recorded to detect the crack behavior with time. The stages of crack formation are filmed by a high-speed photography of the weld pool and solidification process at a speed of about $1000 \mathrm{fps}$. Additionally, some microscopic examinations using Scanning Electron Microscope (SEM) and Electron Probe Micro-Analyzer (EPMA) are performed on the welds. The results helped in establishing a proposed mechanism for the formation of hot cracks in full-austenitic stainless steel welds done on a Fan-shaped test specimen. The proposed mechanism suggests three stages during hot cracking formation; the crack initiation, propagation, and ceasing. The occurrence of a hot crack during welding mainly depends on the way by which the molten zone solidifies, and which solid phase will primarily solidify. This affects, in turn, the segregation of the chemical elements, which found to have a great role in crack initiation. Moreover, the weld metal structure type, together with the thermal stresses in conjunction with the applied strains on the weld joint play a great role in the crack expansion and ceasing. The present work is considered the first trial done to propose a mechanism of hot-cracking formation during welding the Fan-Shaped test specimen using Pulsed-Current Gas Tungsten Arc welding process.
\end{abstract}

Keywords: Proposed Hot Cracking Mechanism, Full-Austenitic Stainless Steel, Pulsed-Current Gas Tungsten Arc Welding, Fan-Shaped Testing Specimen, High-Speed Photography, Electron Probe Micro-Analyzer

\section{Introduction}

Hot cracking or solidification cracking has been investigated in castings, Pellini [1] and Won et al. [2] and in welds, Medovar [3] for several decades. Hot cracking refers to cracking that occurs during solidification of welding, casting at temperatures close to the melting point of the material. The cracking is known to occur both above the liquation temperature - known as super-solidus cracking - and in the solid state, called sub-solidus cracking, Borland [4].
The various types of hot cracks encountered in stainless steel weldments have been classified by Hemsworth et al. [5] Super-solidus cracking may manifested as solidification cracking, occurring in the presence of a liquid phase in the fusion zone, or as liquation cracking in the heat affected zone (HAZ) where it is accompanied by grain-boundary melting. Solidification cracking in weld metals is considered as the most deleterious and is more widely observed than the other types of cracking [6]. The most popular method of hot cracks testing is the Fan-Shaped specimen test, which was originally 
developed by P. T. Houldcroft [7], due to its simplicity, reproducibility, and effectiveness (cracking sensitivity). In addition, it does not require special equipment as it is a selfrestraint specimen, where variable degree of strains along the axis of the specimen are generated $[8,9]$.

Although of many researches had been involved to study in general- the hot cracking mechanisms during welding, the present work is considered the first trial to investigate and propose a hot-cracking mechanism when welding the FanShaped specimen using the PCGTAW process.

\section{Literature Survey}

\subsection{Effects of Solidification Modes of Austenitic Stainless Steel on Hot Cracking}

Austenitic stainless steel welds have many different types of microstructure, according to the number of phases and the way by which it had been solidified. The solidification mode and consequently the room-temperature microstructure are dependent upon the weld composition, i.e. the content of the austenite- and ferrite-forming elements. The balance between them determines how an austenitic stainless steel weld will solidify [10-16]. Therefore, the effects of alloying elements on the solidification mode can be determined by knowing whether the element is austenitizer or ferritizer, according to the following definition, [17]:

Austenitizers: They are austenite stabilizing elements and the power of their effect is measured by the equivalent nickel percentage (Nieq\%), which is equal to:

$$
\text { Nieq } \%=\mathrm{Ni} \%+.5 \mathrm{Mn} \%+.3 \mathrm{C} \%+.14 \mathrm{~N} \%+\mathrm{Cu} \%
$$

Ferritizers: They are ferrite stabilizing elements, and their effect is measured by the equivalent chromium percentage (Creq\%), which is given by:

$$
\mathrm{Creg} \%=\mathrm{Cr} \%+.0137 \mathrm{Mod}+.015 \mathrm{Si}+.02 \mathrm{Nb} \%+.03 \mathrm{Ti} \%
$$

Weldments that solidify as primary austenite are found to be susceptible to hot cracking, while those that formed as primary delta ferrite are relatively resistant to hot cracking [18]. During solidification of weldments as primary austenite, each of $\mathrm{Cr}, \mathrm{Si}, \mathrm{S}$, and $\mathrm{P}$ are rejected outside the solidified part into the liquid, and they exist in a relatively high concentration in form of liquid films of low melting point. During the final stages of solidification, these films are subjected to the shrinkage-induced strains, which result in a crack occurs through the grain boundary at which the film exists. Although that numerous research work have been performed on this subject, contradictions do exist between them about the role of some of the alloying elements.

Figure 1 is originally developed in this work to show the number of publications which had agreed on the role of each alloying element, associated with the number of publications which agreed on the contrary role (if exists) of the same element [19]. It is 'seen from the figure that a good agreement between publications on both detrimental effects of each of $\mathrm{S}, \mathrm{P}, \mathrm{Nb}, \mathrm{Ni}, \mathrm{N} 2, \mathrm{Cu}$ and the beneficial effect of $\mathrm{Al}$ and Mo, while there is no agreement about the role of other elements.

Brooks et al. [20, 21] argued that since solidification cracking is associated mainly with grain boundaries, those factors that affect the nature of the grain boundaries should be more relevant to cracking behavior.

\subsection{Summary of Theories and Hypothesis of Hot Cracking}

Since the year 1936 attempts have been made to approach the understanding of hot crack formation. Hypothesis and theories have been postulated to explain the mechanism of this ambiguous problem. These theories are briefed in the following paragraphs in a historical order.

Most of authors assumed that hot cracking occurs at or slightly above the solidus temperature. They argue that the basic cause of hot cracking is the inability of the semi-rigid network of dendrites, formed during the liquid-solid stage of solidification, to withstand the contraction strains developed during cooling. This assumption of super solidus cracking has led to two major theories: one based on shrinkagebrittleness theory [4], the other on strain [22].

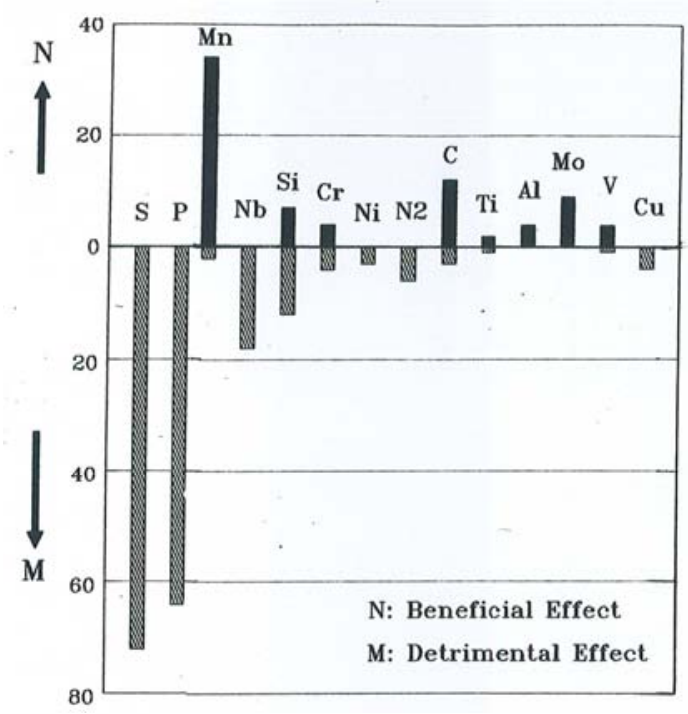

Figure 1. Agreement between publications about the effect of elements on steel weldment cracking. [19]

$\mathrm{N}$ : Number of publications agreed about beneficial effect. M: Number of publications agreed about detrimental effect.

The shrinkage-brittleness theory is the eldest theory for describing the hot cracking mechanism. It was firstly stated in year 1936 by Vero then was developed by Lees, Bochvar, and others, [4]. According to this theory, primary dendrites grow towards each other, while the volume of liquid decreases, until they come into contact and interlock at coherent temperature.

The strain theory was proposed by Pellini et al in the year 1952 [1, 23, 24], who suggested that hot cracking is caused by the localized strains set up by thermal gradients tending to pull apart solid masses of material separated only by continuous thin films of liquid. 
The theory considered only the case of thin films existing near solidus temperature, and neglected more general case of the brittle range.

The assumption of tensile stresses was believed by Arne Apold in the year 1952, [24], that hot cracks are formed due to multi-directional tensile stresses, which arise rapidly in the metal during its contraction. These stresses are aggravated by increased rigidity and by concavity of the bead surface, while convexity moderates these stresses.

Heuschkel hypothesis was stated by Heuschkel in the year 1955, [24], that in some cases cracks occur during the weld thermal cycle, but also may be formed by the stresses imposed upon the weld joint when the material is subjected to high temperature service conditions.

The Principle of Notch mechanism was deduced from the studies of Pozak and Pelleni in the year 1956, [23], in case cracks initiated in the base metal due to the liquation of fusible segregates located at the grain boundaries which adjoin the fusion line of the weld, these cracks develop a high strain concentration on the adjacent solidifying weld metal, and consequently, the cracks extend into the weld metal. If the weld metal is not susceptible to hot cracking - by the virtue of the presence of primary ferrite - the notch mechanism is then ineffective.

In an attempt to reconcile the two theories, Borland has modified them by taking into consideration the ratio of interphase (solid-liquid) and grain boundary energies, as it is clear in the following theory.

The generalized theory of hot cracking is the most reasonable and more complete hot cracking theory and is the one which provided the best understanding of the varied phenomena related to hot cracking, known as the "Generalized Theory", which was ascribed to Borland in the year 1960, [4]. This theory is essentially a combination between the Shrinkage -Brittleness theory of Vero, and strain theory of Pellini [23, 24]. Borland has proposed four solidification stages, which happen subsequently as follows: primary dendrite formation, dendrite interlocking, grain boundary development, and complete solidification.

The wettability concept: the generalized theory of Borland explains that for cracking to occur, it is not only a sufficient condition that a wide freezing range exists, but liquid should also be presented over a relatively wide temperature interval in a distribution which will allow high stresses to be built up between grains, which is called wettability concept [25].

Prokhorov's theory: Prokhorov in the year 1962, [11], defined that the weld metal cracking susceptibility to be related to the temperature and strain rate within the solidifying range of the weld metal.

He defined the temperature range over which cracking will occur as Brittle Temperature Range (BTR)". The upper boundary of this range was defined as the temperature at which liquid phase is prevented from circulating around the grains. The lower boundary is just beneath the solidus and is the temperature below which the strength of the grain boundaries is sufficient to resist the shear stresses arising from contraction.
Theory of Delta-Ferrite was proposed by Hull in the year 1967, [26], it especially concerned the beneficial role of delta-ferrite on hot cracking resistance of stainless steels. The theory postulated that the beneficial effect of delta ferrite in reducing hot cracking of stainless steel welds and castings results from the lower interfacial energy of an austeniticferritic boundary than that of an austenitic-austenitic boundary. It was also reported by Hull that a content of delta ferrite between $(5 \%$ and $10 \%)$ in stainless steel alloy, makes the alloy most resistant to hot cracking.

Backfilling effect was developed by Savage and Dickinson in the year 1972, [27]. They have observed numerous examples of partial healing of hot cracks by the flow of liquid metal from the weld pool into the newly formed crack. This concept summarizes the healing process of macro-hot cracks which nucleate at the solid- liquid interface and grow radially outwards by the influence of external augmented strain.

Arata and Matsuda in year 1977, [28], stated that the solidification cracks are nicely to occur under a combination of strains and strain rates due to the lowest ductility inspite of the strain rate within the higher temperature range of the BTR. Above this range the crack surface morphology showed a dendritic appearance as an evidence of liquid, and they propagate almost instantaneously to metal at the lowest temperature. The cracks may then follow the solidification front by propagating along liquid films at the grain boundaries, [29].

Although the susceptibility of full-austenitic stainless steel to hot cracking has been extensively investigated, there is still no completely explanation for the way by which a hot crack takes place during welding of Fan-shaped test specimen. However, recent observations had been done in the present work concerns the welding of the Fan-shaped cracking test specimen, and suggests three stages of the crack initiation, propagation and ceasing based on specimen geometry.

\section{Experimental Procedures}

Figure 2 shows the dimensions of the Fan-shaped cracking test specimen, [30], which used in carrying out the experiments. Two parts; taper part and constant thickness part distinguish the specimen as shown in the figure. The test material is cold-rolled thin sheets of $3 \mathrm{~mm}$ thickness of full austenitic stainless steel of chemical composition given in table 1. Some experiments are conducted to study the stages of crack formation during the welding pool solidification, using the pulsated current GTAW welding process; under constant pulse welding conditions given in table 2. Two dummy specimens of constant thickness and of the same material are involved in every test. The first is put in front of the test specimen to strike the arc on, in order to get a stabilized arc on the test specimen Figure 3. The second is mounted behind the test specimen to put the arc off few seconds after the end of the test specimen welding. The procedures of these experiments are explained in the 
following paragraphs.

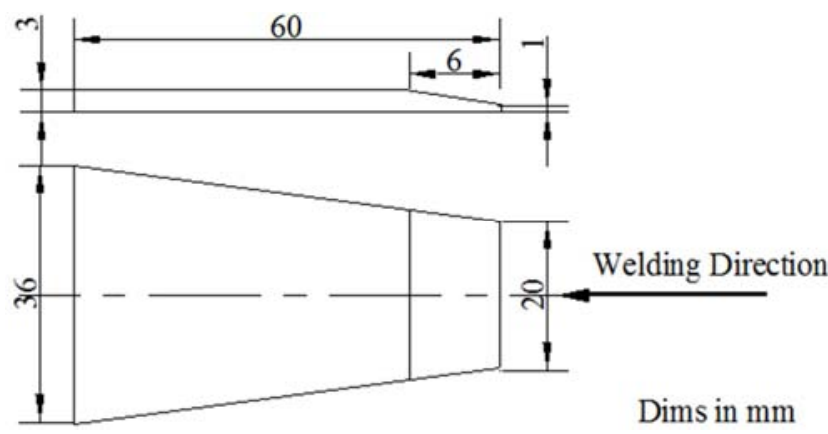

Figure 2. Dimensions of the Fan-Shaped cracking test specimen.

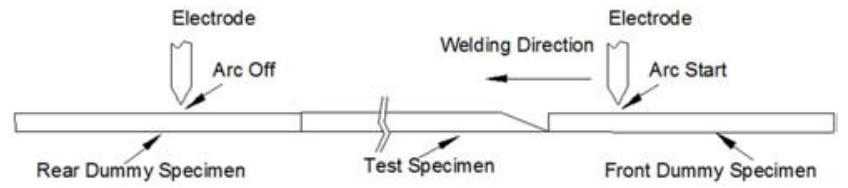

Figure 3. Use of Dummy specimens to strike and put the arc off in front and behind the test specimen welding.

Table 1. Chemical weight composition of the specimen material.

\begin{tabular}{llllllll}
\hline Element & C & Si & Mn & P & S & Cr & Mo \\
\hline Wt \% & 0.057 & 0.465 & 1.25 & 0.021 & 0.002 & 16.47 & 0.17 \\
Element & $\mathrm{Ni}$ & $\mathrm{V}$ & $\mathrm{W}$ & $\mathrm{Cu}$ & $\mathrm{Al}$ & $\mathrm{Nb}$ & $\mathrm{N} 2$ \\
Wt $\%$ & 12.65 & 0.05 & 0.06 & 0.12 & 0.017 & 0.88 & 0.03 \\
\hline
\end{tabular}

\subsection{Recording the Specimen Expansion}

The specimen expansions perpendicular to weld line due to thermal effects, in addition to the transverse expansion due to the crack opening strain, are sensed using two identical inductive pick-ups of contact type, and are recorded on a six channel time-recorder, with two carrier frequency bridges. Additionally, the relative electrode-to-specimen movement is also traced using a $4 \mathrm{v}$ signal to show the start and the end of the specimen welding period.

Figure 4 shows the setup of the transducers mounting, and the specimen clamp on the carriage. The transducers styluses are attached to the specimen using two pins of $2 \mathrm{~mm}$ diam. at a section $1 \mathrm{~mm}$ far from the end of the specimen taper part, as shown in the sketch given in Figure 5. In this figure, the test arrangement is diagrammatically illustrated. The elevation view and the section at A-A shows the details of the 4 volts signal number II, which indicates the start and end of the specimen welding.

Signal I is also of 4 volts, which indicates the start and end of the welding process ( $\operatorname{arc}$ ON/OFF period). Signals III, IV are the outputs of the two transducers. The traces of these signals are sketched as shown in Figure 6. It is seen that the specimen welding - signal II -starts a few seconds after the beginning of the welding process - signal I -, and also ends a few seconds before its end, while signals of pick-ups start with the start of signal II. The two transducers are calibrated using an internal micrometer, which is inserted between the two transducers tips instead of the specimen.
Table 2. Welding Conditions of the experiments.

\begin{tabular}{ll}
\hline Welding speed S, (mm/min) & $\mathbf{1 5 0}$ \\
\hline Pulse current Ip, (A) & 120 \\
Base current Ir, (A) & 60 \\
Average current Iav, (A) & 90 \\
Time ratio $\theta t,(\%)$ & 50 \\
Pulse frequency f, (Hz) & 3.5 \\
Arc Length L, (mm) & 1.0 \\
\hline
\end{tabular}

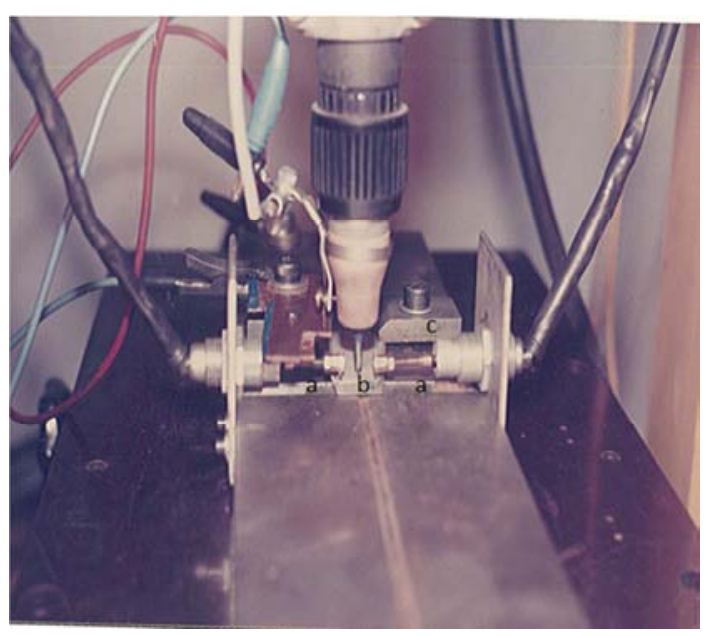

Figure 4. Set up of time recording for cracking specimen strains. a) Two inductive pick-ups, b) Welding specimen and electrode. c) Clamping strips.

\subsection{Studying the Solidification Process Using the High-Speed Photography}

The melting and solidification processes with the time history of crack initiation are investigated by high-speed filming of the welding pool and solidification fronts during the process, through the first $10-15 \mathrm{~mm}$ length of the specimen. Figure 7 shows the set-up of this test. A high-speed $(18 \mathrm{~mm})$ camera is used in this purpose; its maximum filming speed is 2000 frames per second. Figure 8 illustrates the relative position of the camera to the specimen and electrode. It can be seen that the camera lies at the same vertical plane of the electrode, and is oriented to the specimen tip with an angle of $30^{\circ}$ to the horizontal plane. This technique helps to understand how the crack initiates and propagates, to calculate the solidification rate, and to study the movement of the solidification fronts.

\subsection{Effect of Shifting the Bead CL from the Specimen CL}

As shown in Figure 9, the welding centerline (CL) is shifted from the specimen centerline with variable distances, in order to study the coherence between the crack CL and the confrontation line of the solidification fronts. One condition of this experiment is filmed using the H. S. camera for monitoring.

\subsection{Effect of Welding Bead Length on Crack Formation}

The cracking test specimens are welded for different welding lengths. The maximum length of the formed crack is measured for each case, keeping the welding conditions constants. This test helps to predict how the crack propagates through the specimen. 


\subsection{Chemical Segregation Tests of Crack Formation}

In order to evaluate the roles of the chemical compounds of different elements, some micro-segregation tests are performed at the different crack zones of the previously welded and filmed specimens. The considered elements are $\mathrm{Mn}, \mathrm{P}, \mathrm{S}, \mathrm{Nb}, \mathrm{Mo}, \mathrm{Si}$ and $\mathrm{Ni}$. The scanning transmission electron microscopy (STEM), fitted with four energy dispersive $\mathrm{x}$-ray spectrometers (EDS) operating at $20 \mathrm{Kv}$, with minimum beam diameter of $5 \mu \mathrm{m}$ is utilized in the experiments. As well as the electron-probe micro-analyzer (EPMA) operated at an accelerating voltage of $20 \mathrm{kv}$, and a nominal specimen current of $0.25 \mathrm{NA}$ is also utilized in investigating the elements segregation in the vicinity of the crack tip. All segregation measurements are carried out on the weld metal at the sectional horizontal plane.

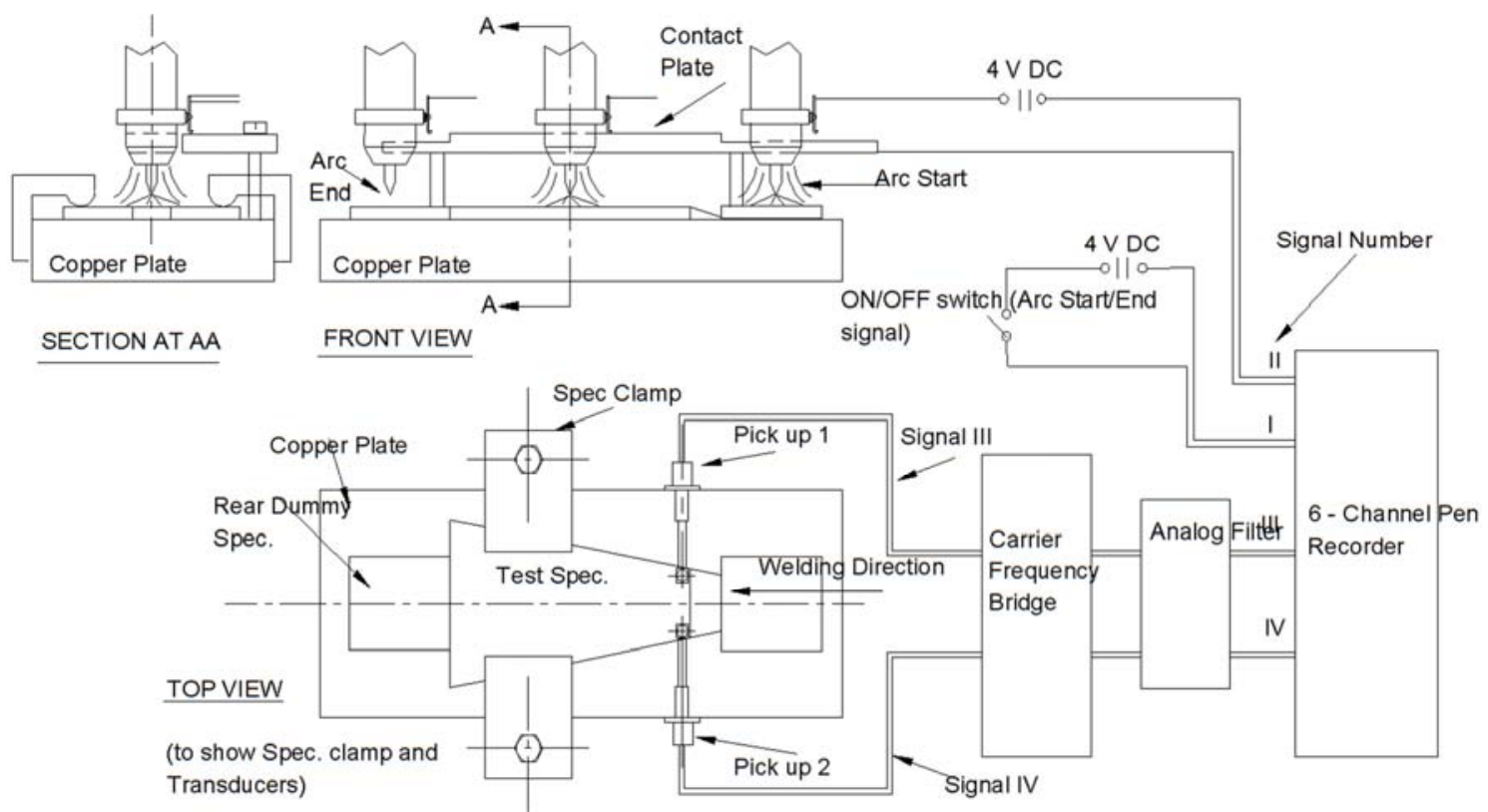

Figure 5. Sketch of the system used in recording the test specimen strains.

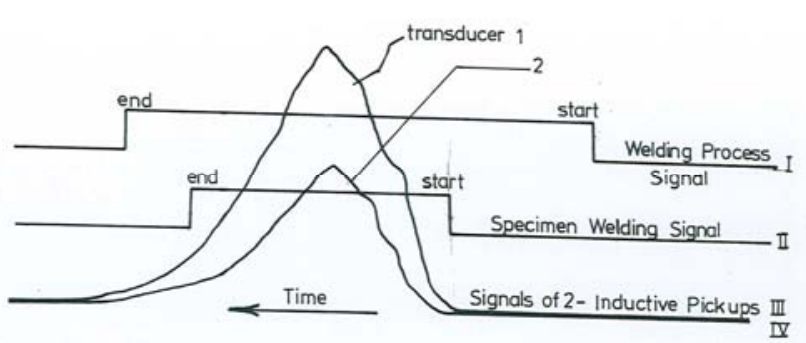

Figure 6. Schematic representation of the four-recorded signals, (I-IV).

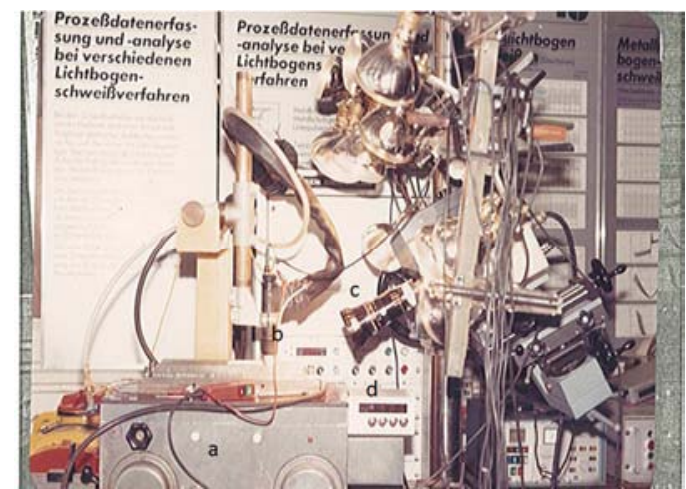

Figure 7. High speed filming set up of solidification process.

a) Welding carriage, b) Electrode-holder, c) High speed camera. d) Welding speed meter.

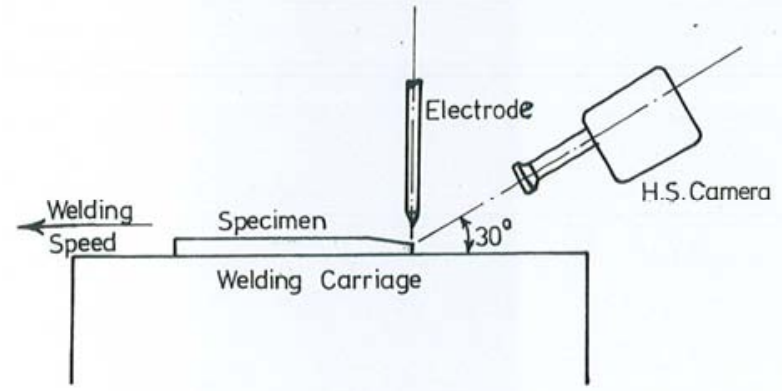

Figure 8. Relative position of the high-speed camera with respect to the welding specimen.

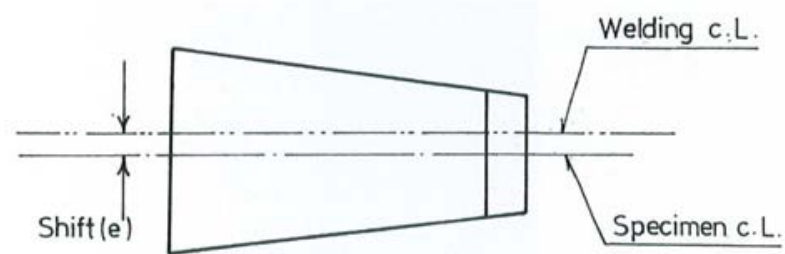

Figure 9. Shifting the welding line with respect to the specimen centerline.

\section{Results and Discussion}

The results of the accurate experimental observations and measures on the crack formation of Fan-Shaped specimen; which clearly demonstrate that the solidification cracking of 
this specimen is a result of the accumulation of macroscopic tensile cross-strains in a microscopic inter-granular liquid film of segregation at the final stage of the weld metal solidification.

\subsection{High-speed Photography}

Figure 10 shows the photographs obtained when filming the welding process. The figure shows photographs starting by the zero time moment, photo No. 1, which represents start of melting. Then solidification starts in photo No. 2 at 1444 milli-seconds (ms) later, in which two fronts are formed at both sides of the bead. Photographs No. 3-6 shows the progress of both fronts so that they approach each other and the remainder liquid is included in the gap between them. Two solidification fronts are clearly appear in photo No. 4. Photograph No. 6 represents the moment of meeting of the two solidification fronts. At the moment of $3890 \mathrm{~ms}$ a crack shape is observed in photo No. 7. As the electrode advances, the crack expands through the bead, keeping a nearly constant distance between its tip and the trailing pool edge as it is clear in photos after No. 7. Photos No. 7 and 8 emphasize that the crack starts at the interface between the two solidification fronts.

Careful observation of the photographs in Figure 10 show that the advancement of both fronts is symmetric, so that the crack is formed on the centerline of the bead. High-speed photography helps to measure the progress distance of the solidification front Ls, which is plotted against time, Figure 11, for two power conditions of pulsated and un-pulsated currents. It is clear from the figure - as logically expected that the rate of progress of solidification fronts is higher at the chamfered part of the specimen than that at its rest part of the constant thickness. Comparing results of pulsated and unpulsated current tests it can be concluded that the effect of pulse on the rate of solidification is more substantial than that of changing the power.

The three critical solidification moments (solidification start, fronts meeting and crack occurrence moments), are measured and compared with others for different welding conditions in order to study the effect of power and pulse application on them. Figure 12 reveals that these critical moments occur earlier for lower power $(206 \mathrm{~J} / \mathrm{mm})$ than those for higher power conditions, (296 and $308 \mathrm{~J} / \mathrm{mm}$ ). Also for pulsed current these critical moments are earlier than unpulsed current conditions. It can be also deduced from the figure that the time lag between the crack occurrence and the fronts meeting increases as the welding power increases. Although some trials were done to study the metal transfer [31], and the progress of solidification fronts in normal welding processes using the high speed photography technique [29, 32, 33], nobody have yet tried to apply this technique in pulsed GTAW process of austenitic stainless steel on the Fan-Shaped test specimen.

\subsection{Expansions Test Results}

The results of recording the specimen expansions during welding show the same values and emphasized the results obtained previously by high-speed photography. Figure 13 shows a sample of typical records of the specimen expansion during welding. The record contains four signals; signal I represents the welding period (arc On/Off signal), which starts at moment $\mathrm{A}$ at the middle of the front dummy specimen, and ends at the moment $\mathrm{H}$ at the middle of the rear dummy specimen. Signal II represents the period of welding the test specimen. It starts at the zero time moment B, (at which the specimen tip starts to melt), and ends at moment $\mathrm{F}$, at which the welding of the specimen is ended.

Signals III and IV are the outputs of the two inductive pickups; noting that they are plotted with different scales. They are characterized by five stages as follows: BC period, which represents the specimen gradual expansion before crack occurs. The sudden expansion at moment $\mathrm{C}$ represents the crack initiation or occurrence. It is clear that this stage (BC) is longer for conditions of higher welding power than those of lower power. Sometimes it is noted that point $\mathrm{C}$ cannot be distinguished; this means either there was no cracks for the selected conditions, or the crack lateral expansion is not sensed by the pickups. The second period is $\mathrm{CD}$, which represents the completion of the specimen expansion. The third period is DE, which represents the cooling contraction. Fourth stage is EF, which is thought to be due to the specimen distortion due to the expected residual thermal stresses. The last period is that after moment $\mathrm{F}$ and represents contractions due to the specimen gradual cooling down to room temperature.

It was mentioned by Jialie et al [34], in his experiment on welding two rectangular clamped strips that the crack occurrence is probably due to thermal stresses found on the specimen. In this investigation a qualitative but incomplete interpretation for the crack occurrence is presented.

\subsection{Shifted-centerline Weld Bead}

In order to confirm the forgoing concept, that the crack usually occur at the interface of the two solidification fronts; an experiment is done by shifting the weld bead centerline (CL) from the specimen CL. This means that the cooling rate on the weld bead sides will be unsymmetrical.

The aim of this experiment is mainly to investigate whether the crack and/or segregation will be at the plane of bead symmetry, or will follow the plane of the two solidification fronts interface. Figure 14 shows sample results of high-speed photography carried out with $4 \mathrm{~mm}$ shift distance between the welding bead CL and the specimen CL, in which photo No. 3 shows the start of solidification on one side of the bead in $1250 \mathrm{~ms}$ earlier than the other side, and therefore the two solidified parts are not equal. The interface between the two fronts in this experiment is found shifted about $1.4 \mathrm{~mm}$ from the bead CL, Photo No. 7 .

On varying the shifting distance $\mathrm{E}$ between the weld bead $\mathrm{CL}$ and the specimen $\mathrm{C}$. L. Figure 15 under the condition of constant welding power, a good correlation between this distance $\mathrm{E}$ and the crack shift $\mathrm{e}$ - the distance between the crack CL and the weld bead CL - is found as shown in Figure 
16. It appears from the figure that as distance $\mathrm{E}$ increases, distance e increases. This behavior can be attributed to the high heat dissipation found through the specimen material in direction opposite to the shift E.

According to the chronograph from which these pictures in Figure 14 are taken, the time of the crack occurrence is measured and is found at $3992 \mathrm{~ms}$, measured from the zero time moment. The crack occurrence in this case is $938 \mathrm{~ms}$ lagging that in case of symmetrical welding. Figure 17 illustrates that all critical moments of the solidification process are retarded due to bead CL shift E.

This experiment confirms that the crack always takes place at the interface between the two solidification fronts elsewhere it will exist; as well as it lags the moment of fronts meeting by a constant amount of milliseconds.

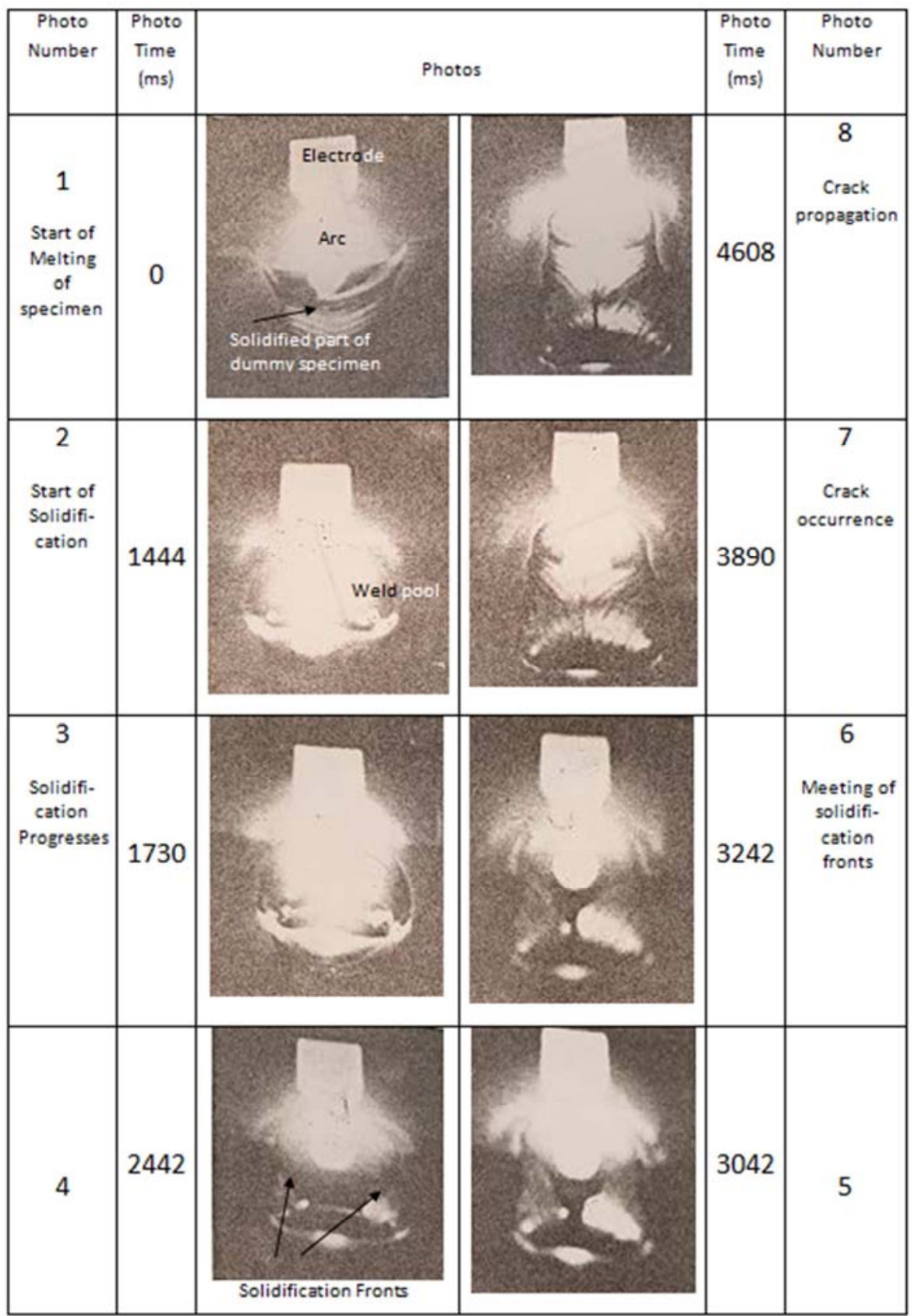

Figure 10. High speed photographs of the solidification process, Pulse conditions: $I r=60 \mathrm{~A}, I p=120 \mathrm{~A}, f=3.5 \mathrm{~Hz}, \theta t=50 \%, S=150 \mathrm{~mm} / \mathrm{min}$.

Figure 17 Shows three different behaviors; the first is that the solidification starts as earlier as the shift increases. This behavior can be interpreted by the greater heat dissipation takes place in the side opposite to shift direction. The second is that fronts meeting moment is retarded as the shift increases. This behavior is explained as the shift increases, the amount of metal solidified on the side opposite to shift direction will remarkably increases. Which leads to a longer time for fronts to meet behind the bead CL. The third is that the crack occurrence is lagging the fronts meeting moment almost by the same amount of milliseconds. Keeping in mind that the line of zero time (zero of Y-axis) represents the 
moment of start of specimen melting for all experiments, as it $\quad$ was declared on figure 12 .

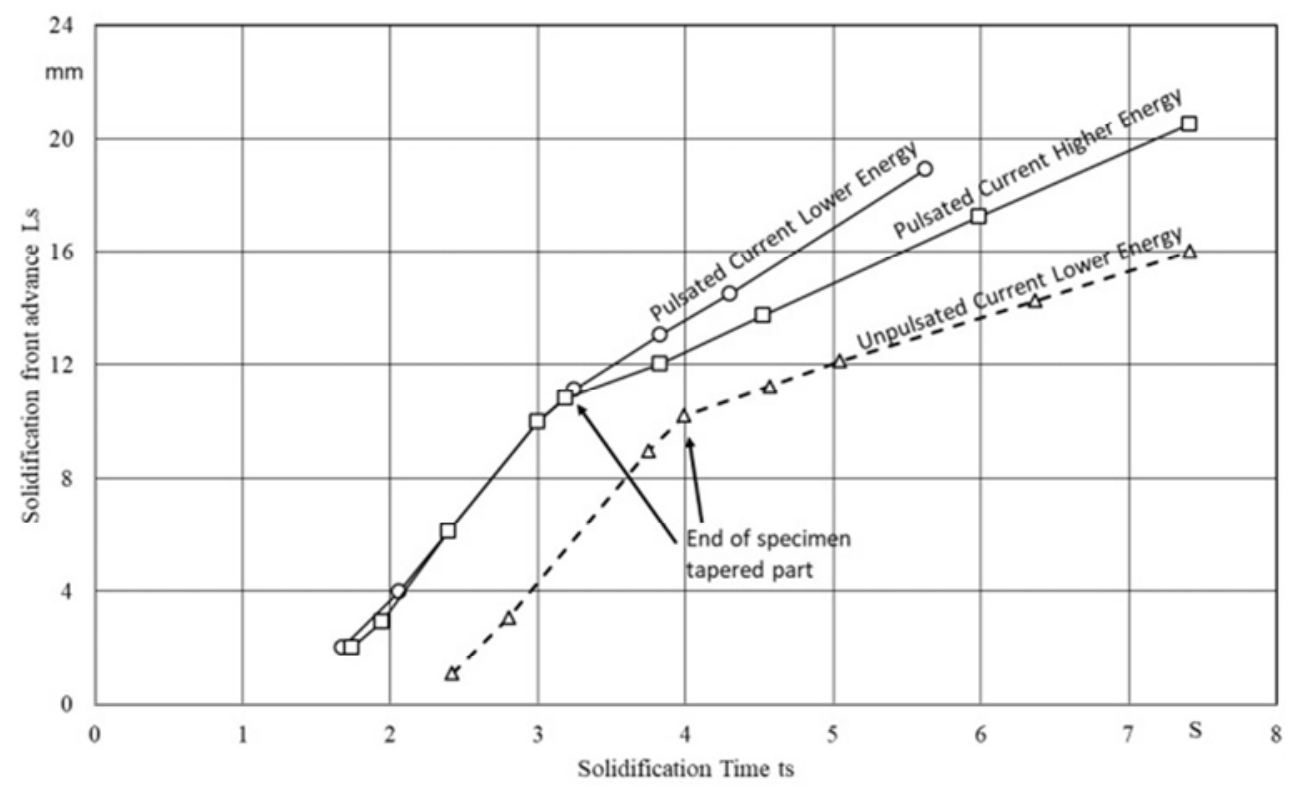

Figure 11. Solidification advance through the welding process versus time.

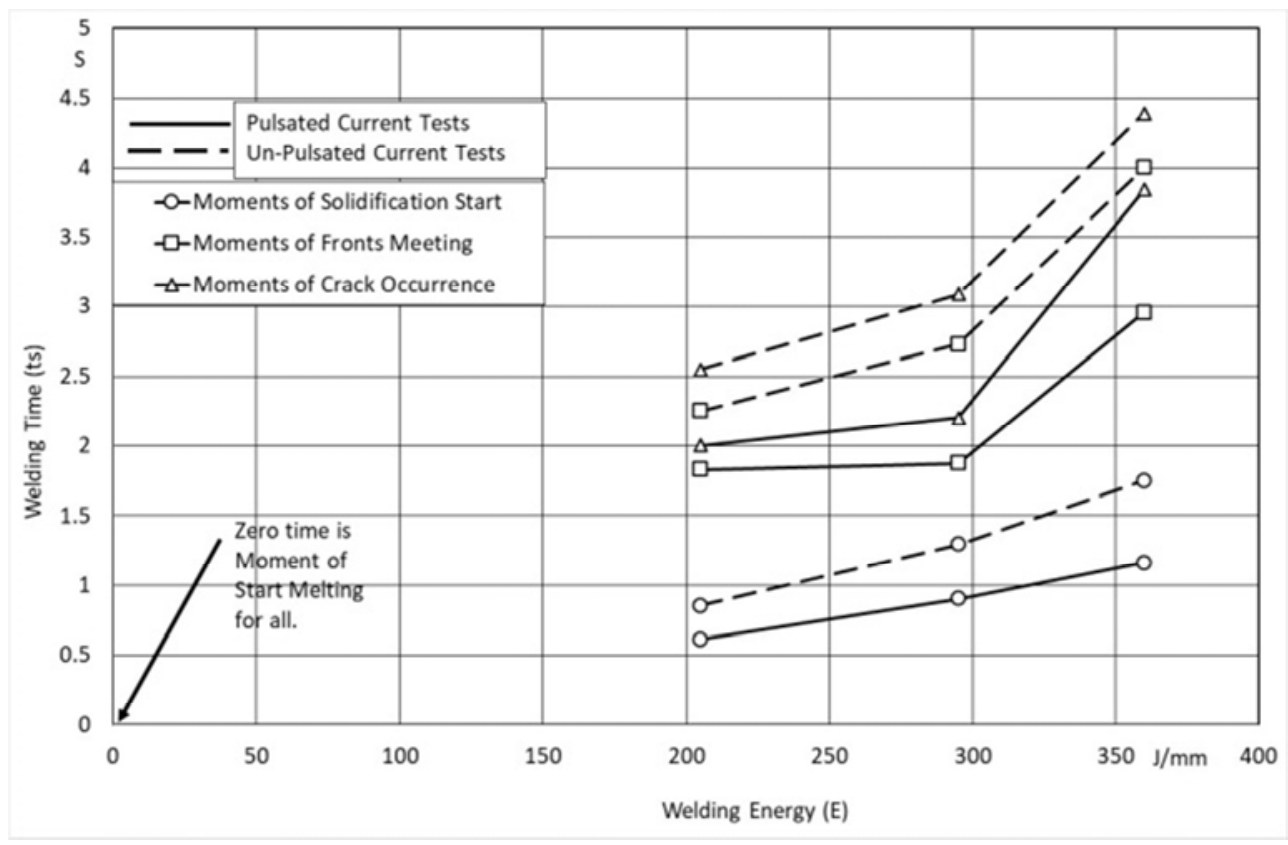

Figure 12. Effect of welding energy and current pulsation on the momental procedure of the solidification process.

\subsection{Effect of Welding Bead Length on Crack Formation}

The cracking test specimens are welded for different welding lengths. Maximum length of the formed crack is measured for each case, keeping the welding conditions constant.

Although there is a lot of work tackling the cracking susceptibility of steel, nobody tried to find the relation between welding length and the length of the propagated crack. Therefore, a trial is done in the present work to correlate these two factors. In this trial the welding length, lw, with constant welding power, is varied under the same welding conditions, in order to expose the specimen to variable conditions of thermal stresses, and explore the course of the crack propagation. Figure 18 gives the relation between the welding length $1 \mathrm{w}$, and the propagated crack length lc. It can be deduced that as $1 w$ increases, the thermal stresses accumulated in the whole specimen also increase, resulting in an increase of the crack opening force, which leads in turn to increasing the resulted crack length lc. When welding the full length of the specimen, the crack length lc reaches its maximum value $(43 \mathrm{~mm})$, at welding bead length $(\mathrm{lw}=60 \mathrm{~mm})$. This test helps to predict how the crack propagates through the specimen. 


\subsection{Results of Chemical Segregation Tests}

A scan tracing of the concentrations of those elements thought to be dangerous for cracking, are performed across the specimen centerline using EDS system, Figure 19. Investigated points $A$ to $D$ are chosen on the following grain boundaries; at crack site (point A), on fusion zone vicinity (point B), on heat affected zone (point C), as well as on the base metal (point D) as shown in the figure. The segregation profiles in counts per seconds when scanning an area of 25 $\mu \mathrm{m}^{2}$ at each point are shown in the figure. From the concentration profiles it can be easily noted that some elements show a slight increase, e.g. Si and Ni, while others e.g. Mn shows a slight decrease. While $\mathrm{Nb}$ and $\mathrm{Cr}$ experience a substantial increase of about 4 and 1.3 folds of their nominal values at the base metal respectively, which are considered as crack promoters. The same results were attained with nearly similar conditions by other investigators [14, 26, 35-37]. Referring to the high-speed photography results, it can be deduced that the crack occurs at the interface between two solidification fronts. Results of elements segregation can give an explanation to this phenomena which may be attributed to the increase of some decisive elements or compounds such as $\mathrm{Nb}$ or $\mathrm{Nb}$ carbide and $\mathrm{Cr}$ on grain boundaries close to site of the crack.

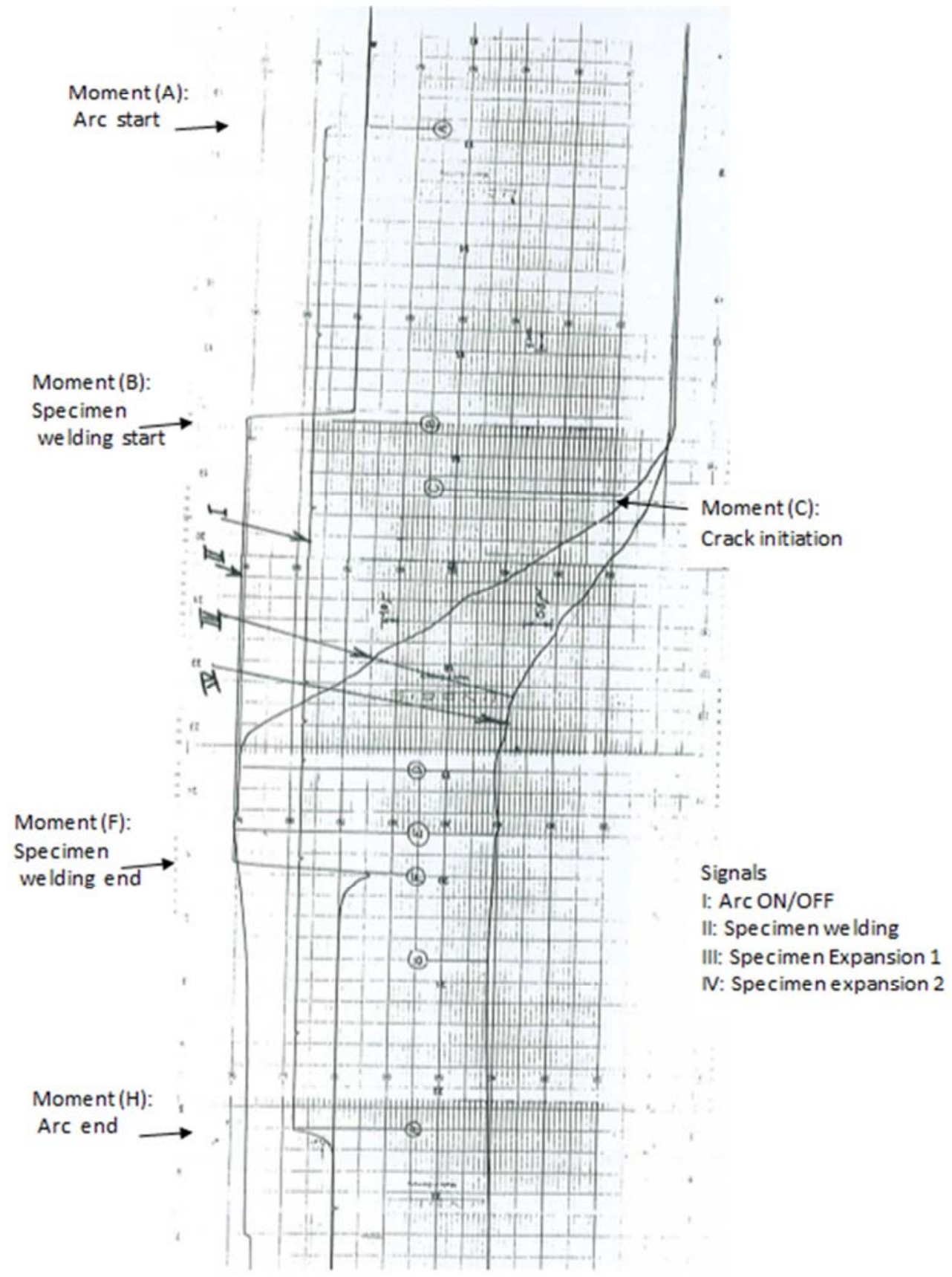

Figure 13. Time record of expansion of cracking specimen Pulse conditions: $I p=140 \mathrm{~A}, \mathrm{Ir}=80 \mathrm{~A}, f=3.5 \mathrm{~Hz}, \theta t=50 \%, S=150 \mathrm{~mm} / \mathrm{min}$. 


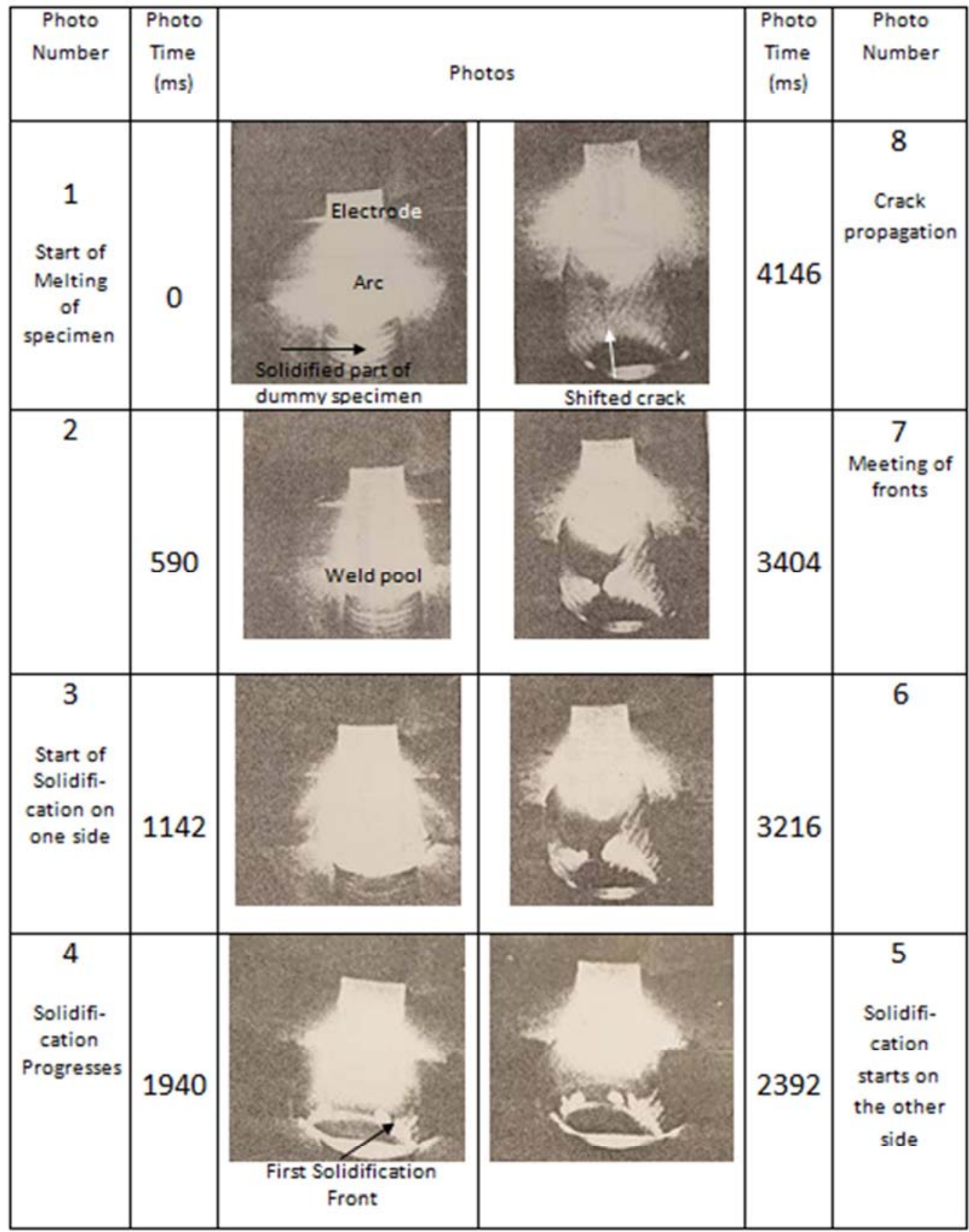

Shift $=4 \mathrm{~mm}$, Pulse conditions: Ip $=120 \mathrm{~A}, \mathrm{Ir}=60 \mathrm{~A}, \mathrm{f}=3.5 \mathrm{~Hz}, \theta \mathrm{t}=50 \%, \mathrm{~S}=150 \mathrm{~mm} / \mathrm{min}$

Figure 14. High-speed photographs of the solidification process with shifted welding $C L$.

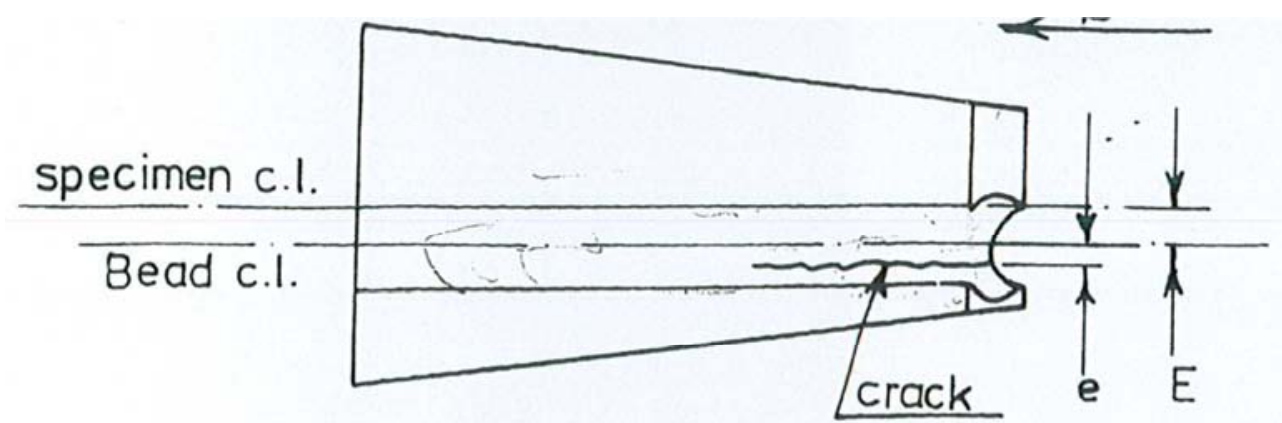

Figure 15. A Sketch to illustrate the bead shift $E$ and the crack shift $e$. 


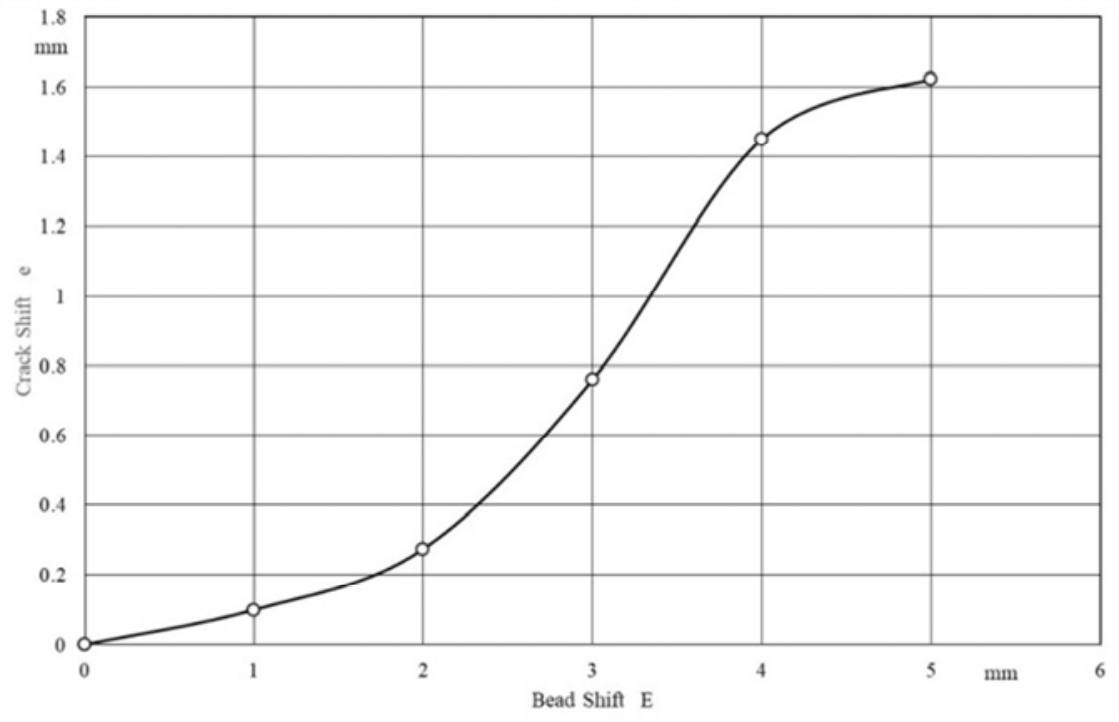

Figure 16. Effect of the bead shift $E$ on the crack shift $e$.

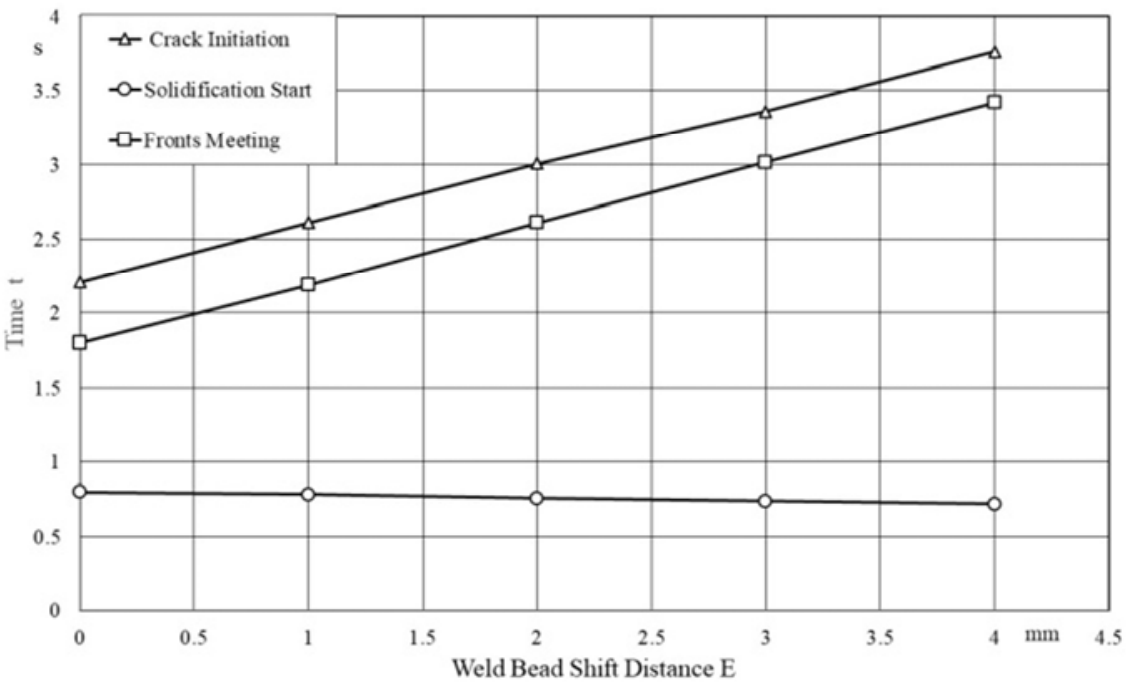

Figure 17. Effect of weld bead shift distance E on the critical solidification moments.

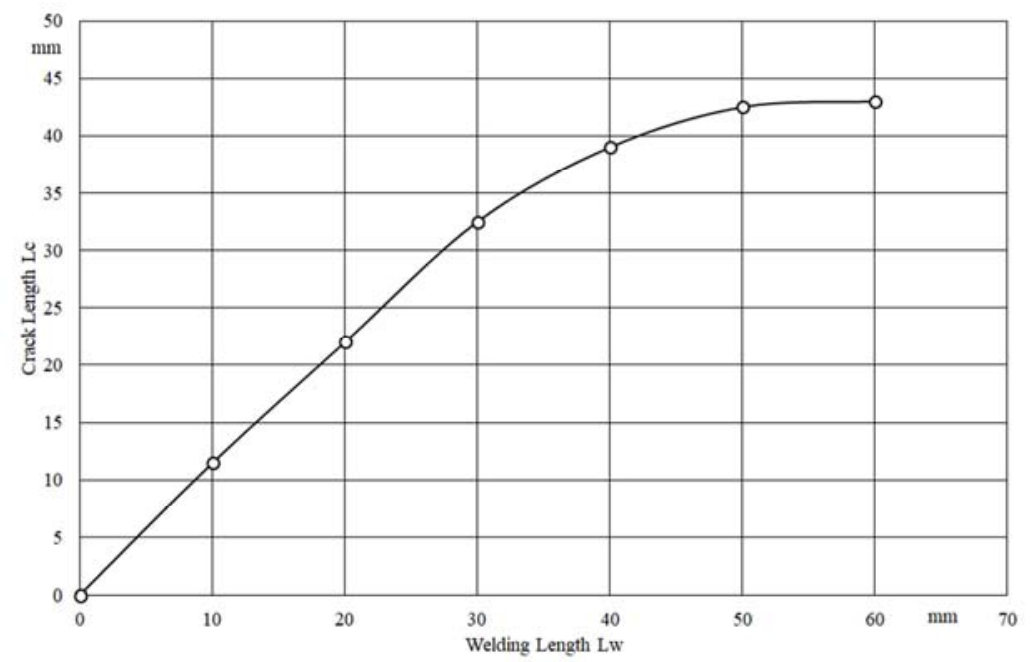

Figure 18. Effect of welding length Lw on the crack length Lc Pulse conditions: $\mathrm{Ir}=60 \mathrm{~A}, \mathrm{Ip}=120 \mathrm{~A}, \theta t=50 \%, f=3.5 \mathrm{~Hz}$. 


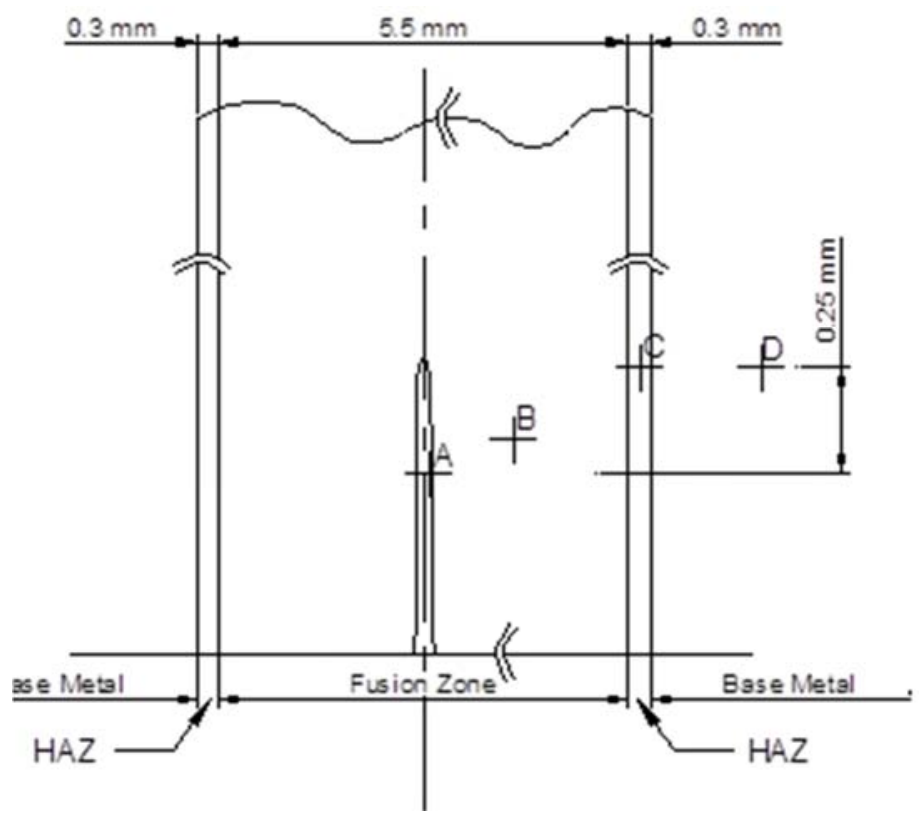

(A) Locations of segregation searches
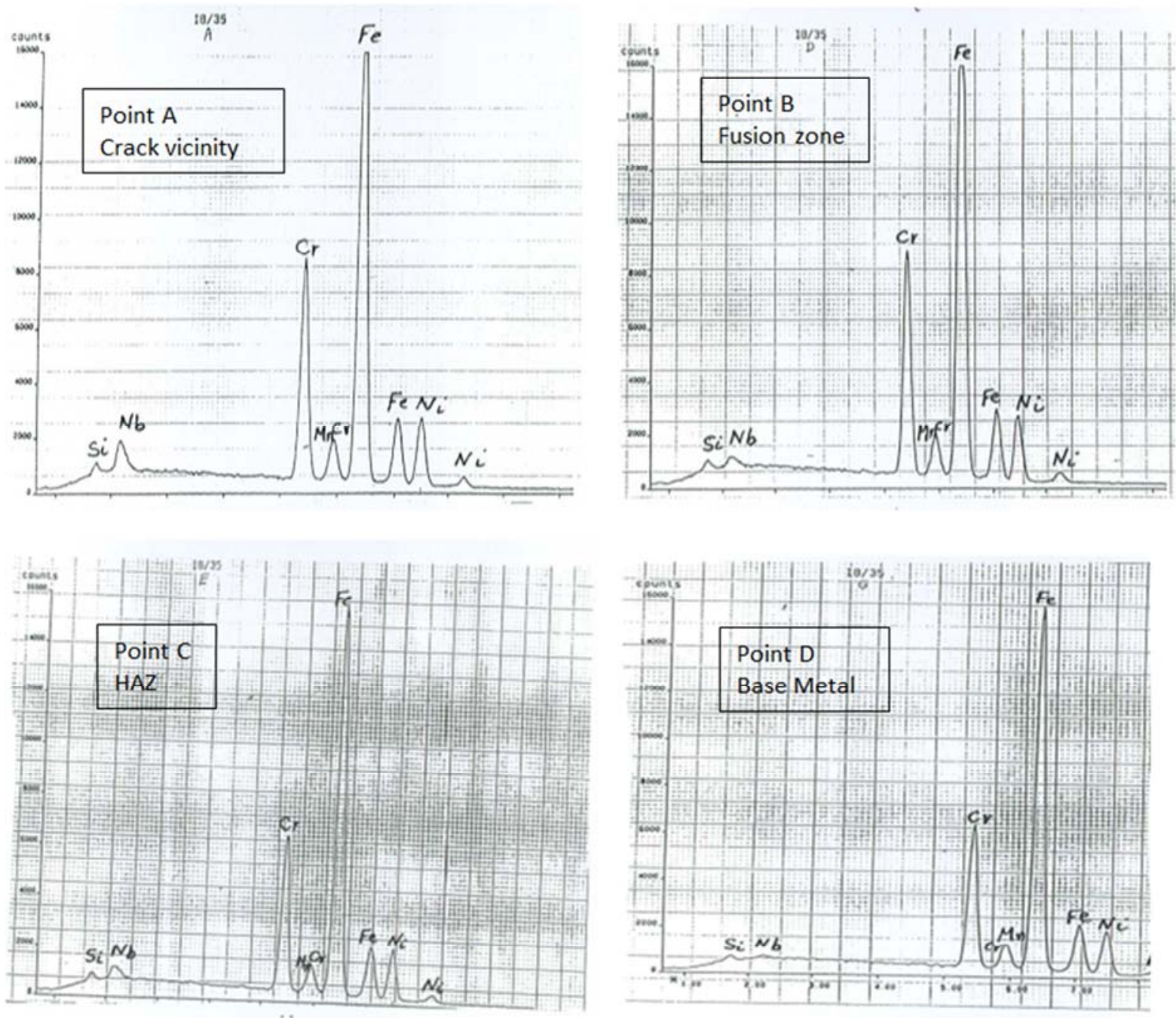

(B) Segregation results

Figure 19. EDS segregation results at different locations of the weld bead, Pulse conditions: $\mathrm{Ir}=60 \mathrm{~A}, f=10 \mathrm{~Hz}, \theta t=25 \%$. 


\subsection{Investigation of Crack Propagation}

In order to illustrate the crack propagation through the weld bead, the tracing of various elements is conducted to investigate their segregation on the grain boundary at the crack tip vicinity, using STEM and EPMA techniques.

Results of STEM are shown in Figure 20; it illustrates a photomicrograph showing the selected location $\mathrm{A}$ on the crack, where the segregation test is performed, in addition to another location is selected on the base metal. Concentration levels of $\mathrm{Si}, \mathrm{Ni}, \mathrm{Cr}$ and $\mathrm{Nb}$ at the selected locations are traced. Comparing the two groups of concentration levels it is noticed that $\mathrm{Si}$ shows no change in concentration, while Ni and $\mathrm{Cr}$ show slight depletion, and a substantial enrichment of $\mathrm{Nb}$ is evident at crack location.

Many investigators have concentrated their work on the role of $\mathrm{S}$ and $\mathrm{P}$ in crack susceptibility [10, 38-41]. They investigated mostly materials or alloys containing $\mathrm{S}, \mathrm{P}$ in the ranges of $(0.095-0.220)$ and $(0.082-0.242)$ respectively. The levels of these elements in the fully austenitic stainless steel in this work are very low $(0.021 \mathrm{p}, 0.002 \mathrm{~S})$. On the other hand, it was noted in previous literatures that $\mathrm{Nb}$ precipitates on grain boundaries as Nb-Carbide [11, 22, 42-44], which has a high brittleness and results in a brittle grain boundary [12, 13, 36, 45]. Most authors recognized Mn as a crack inhibitor, because it reduces the harmful effects of S and P by forming compounds with them, consequently reducing their segregation [11, 13-15, 45-48]. There is no agreement in literature about the role of $\mathrm{Ni}$ in the cracking susceptibility. Some literatures $[49,50]$ considered it as a detrimental element, while the other [16] stated that it has no effect. An EPMA test is done twice on two areas each of $5 \mu \mathrm{m}^{2}$ inside the fusion zone; the first location is chosen located at $10 \mu \mathrm{m}$ in front of the crack tip at a grain boundary extending in alignment of the crack CL, as shown in Figure 21. The second location is selected $3 \mathrm{~mm}$ away from the crack, inside the fusion zone. Comparing the two results, it is clear that an enrichment of $\mathrm{Nb}$ and/or its compounds is present along the grain boundary extending in front of the crack tip vicinity.

Many of the literatures [11, 22, 42-44, 51-53] documented that $\mathrm{Nb}$ exists in austenitic stainless steel in the form of its carbides. Figure 22 shows also many of $\mathrm{Nb}$ and/or $\mathrm{Nb}$ carbide precipitates (designated by white areas) at the fissured grain boundary along the path of the crack under different welding conditions.

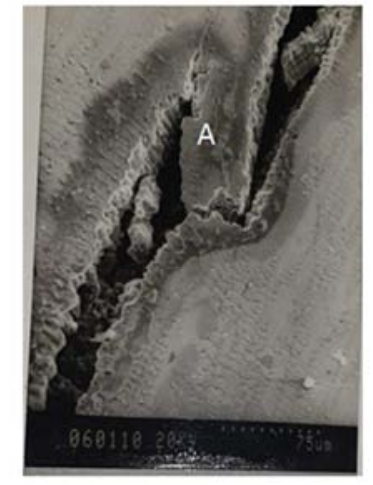

A- Location A of STEM segregation test, [x400]
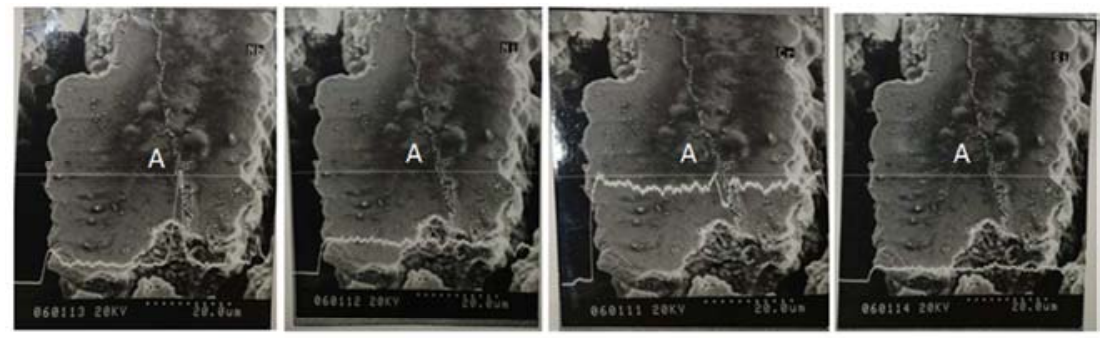

B- Segregation results at location A, on crack, [x1.5k]
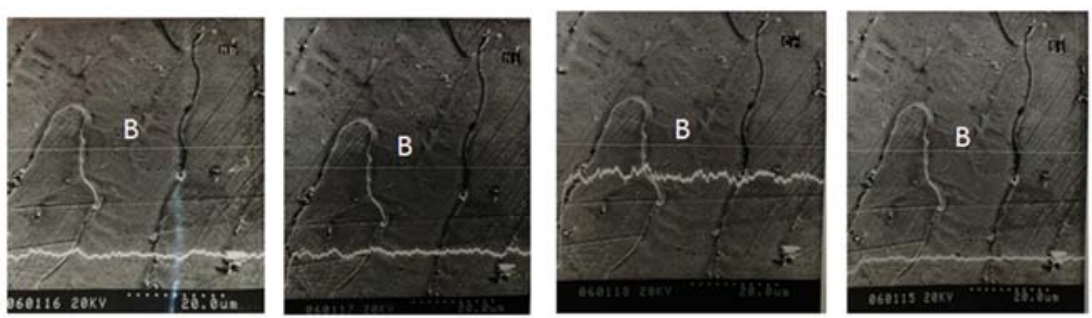

C- Segregation results at location B, on base metal, [x1.5k]

Figure 20. STEM segregation results at crack zone and base metal, in order of: $\mathrm{Nb}, \mathrm{Ni}, \mathrm{Cr}$, Si from left to right. Pulse conditions: Ip $=120 \mathrm{~A}, \mathrm{Ir}=20 \mathrm{~A}, \mathrm{f}=10$ $H z, \theta t=70 \%$.

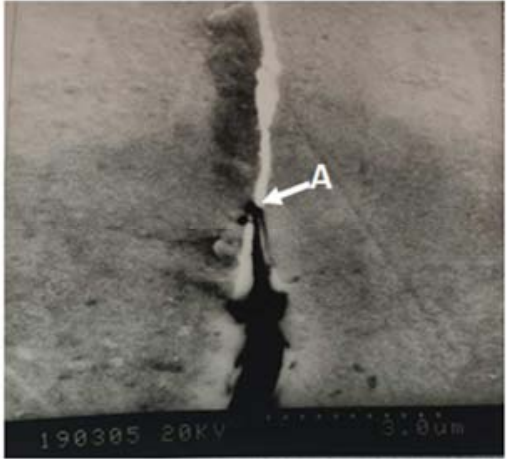



Specimen Using Pulsed-Current Gas Tungsten Arc Welding Process

B)
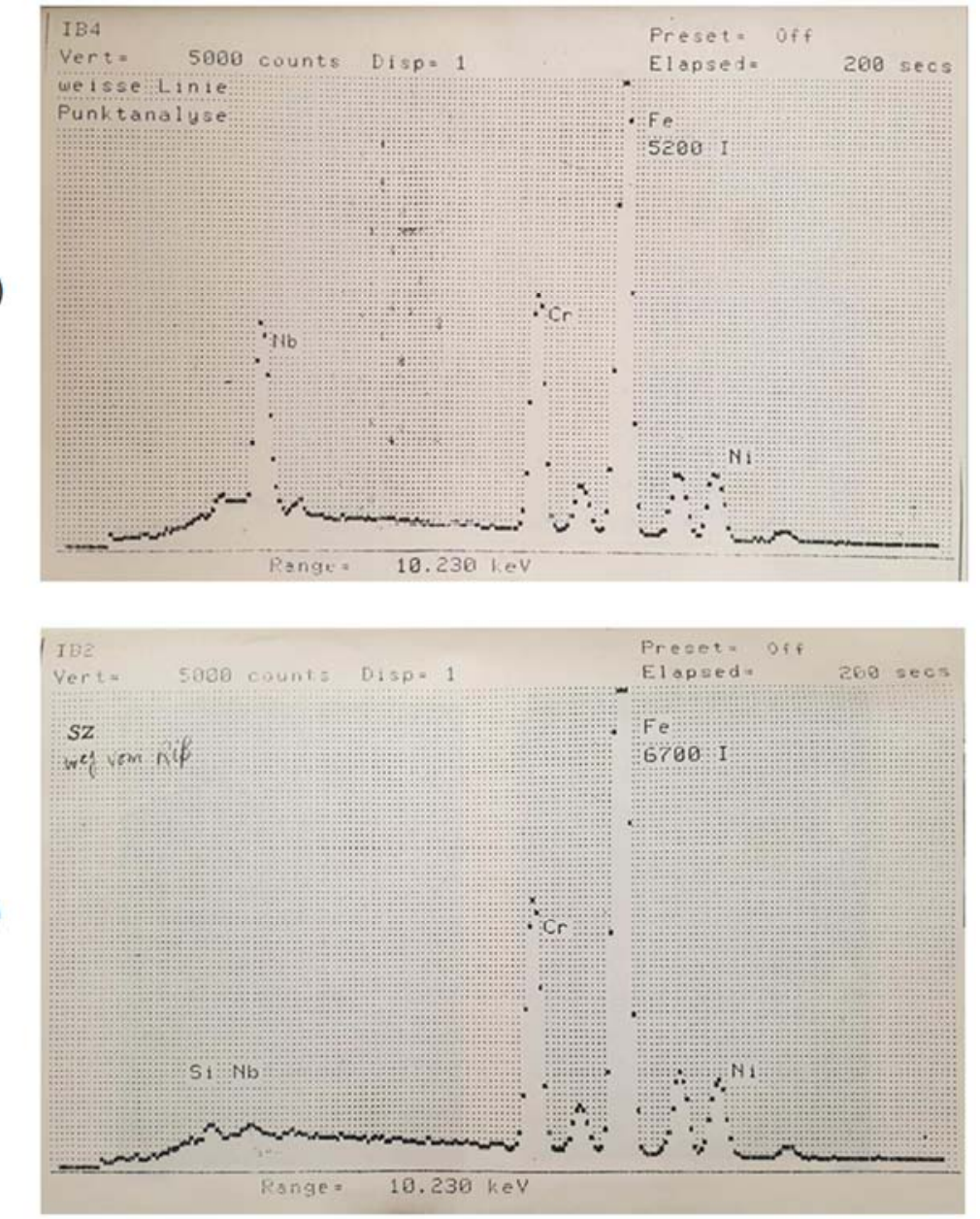

Figure 21. EPMA segregation results; pulse conditions: I $=120 \mathrm{~A}, f=10 \mathrm{~Hz}, \theta t=25 \%$.

A- Location at point A $10 \mu \mathrm{m}$ in front of crack tip [x10k].

B- Results at point A.

C- Results at the middle of fusion zone $3 \mathrm{~mm}$ in advance of the crack tip.

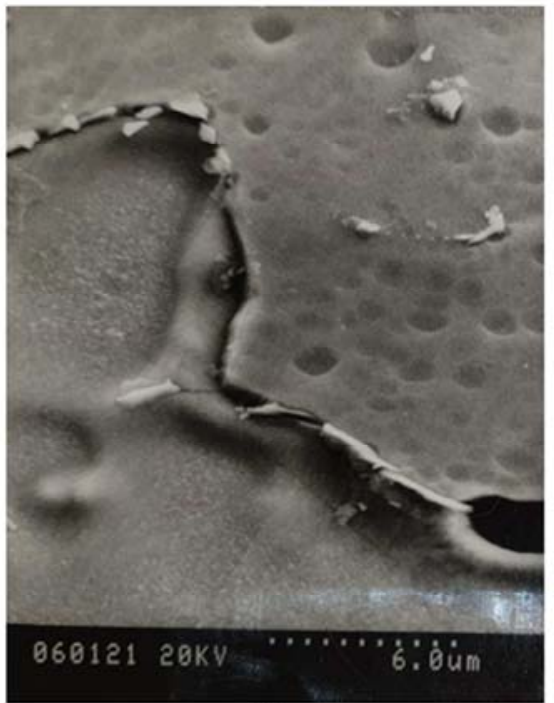

(A)

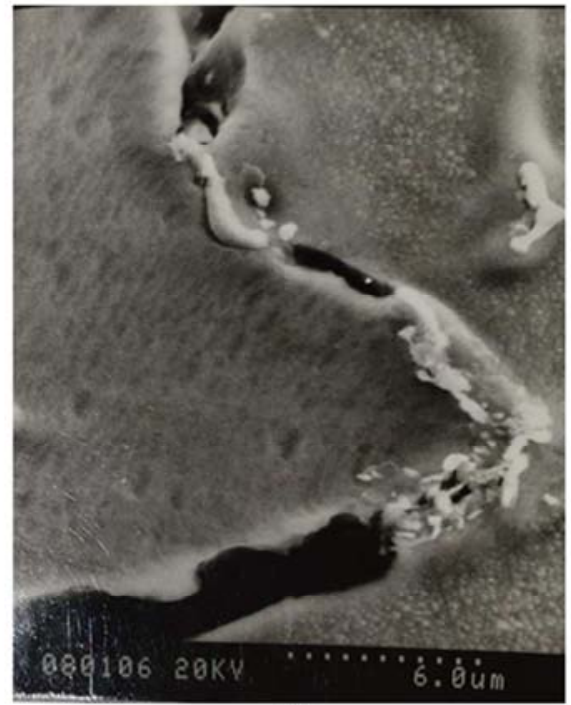

(B)

Figure 22. Fissured grain boundaries with highly Nb precipitations in front of the main crack tip in white color.

A) Specimen of pulse conditions: Ir $=20 \mathrm{~A}$, Ip $=120 \mathrm{~A}, \mathrm{f}=10 \mathrm{~Hz}, \theta \mathrm{t}=70 \%$

B) Specimen of pulse conditions: $\operatorname{Ir}=60 \mathrm{~A}, \mathrm{Ip}=120 \mathrm{~A}, \mathrm{f}=0.2 \mathrm{~Hz}, \theta t=50 \%$ 


\section{Proposed Cracking Mechanism}

Based on the previous literatures together with the forgoing experimental studies, a crack mechanism including three cracking stages during the welding of Fan-Shaped test specimen is suggested as follows.

\subsection{Crack Initiation}

Referring to investigations carried out on both shifted and unshifted beads it can be concluded that the solidification of the Fan-Shaped specimen starts with two fronts, one at each bead side. There are two principal processes occurring together since the first moment of solidification, as seen in the flow chart given in Figure 23. First, is the generation of contraction internal stresses on each of the solidified parts, which accumulate and increase as temperature goes down. As the process is going on by time, the specimen width is increased and accordingly the contraction of solidified parts increases which in turn results in larger accumulated thermal stresses on the grain boundaries (Sacc). Second, is the rejection of the solute elements takes place at the first moment of solidification which have low solubility with the primary solidified $\gamma$ phase into the liquid metal. Once the two solidification fronts meet, a liquid film of high solute concentration is formed at the fronts interface (grain boundary). As soon as this film starts to solidify, it gains a low strength which increases to its maximum value ( interface) as cooling progresses.

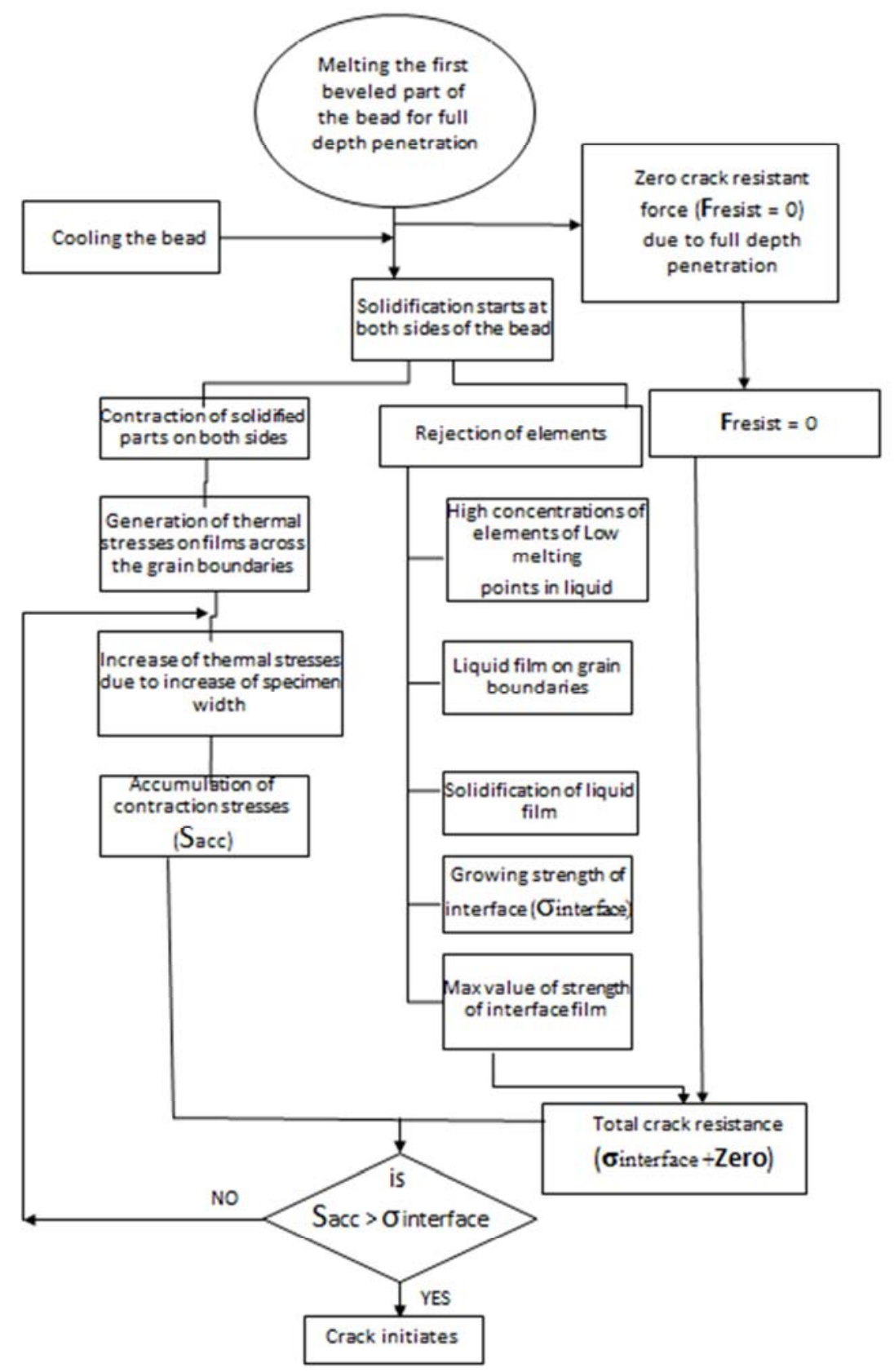

Figure 23. Flow chart of the first stage of the proposed mechanism; "crack initiation", when welding the beveled part of the Fan-shaped specimen. 
The race between these two rates will define the end state. If the rate of growing of the interface strength is higher than that of the accumulated internal stresses due to contraction between the two fronts, no failure occurs (i.e. no crack will take place). On the contrary, if the rate of accumulated thermal stresses is higher than the growing strength of the interface, failure will take place in the form of a crack initiation. The initiation stages can be schematically interpreted as shown stepwise in Figure 23.

Based on the abovementioned discussion, the crack initiation will occur if the accumulated thermal stresses exceed the grain boundary strength i.e. Sacc $>$ ointerface.

\subsection{Crack Propagation}

Referring to the results obtained previously, it may be concluded that the accumulated thermal stresses produce an opening deflection force, which acts to open the initiated crack. This opening force helps the crack to follow the solidification front and propagate along the fissured grain boundaries of high concentration of $\mathrm{Nb}$ and/or its compounds, as long as Sacc > ointerface, and the weld bead has full penetration, Figure 24.

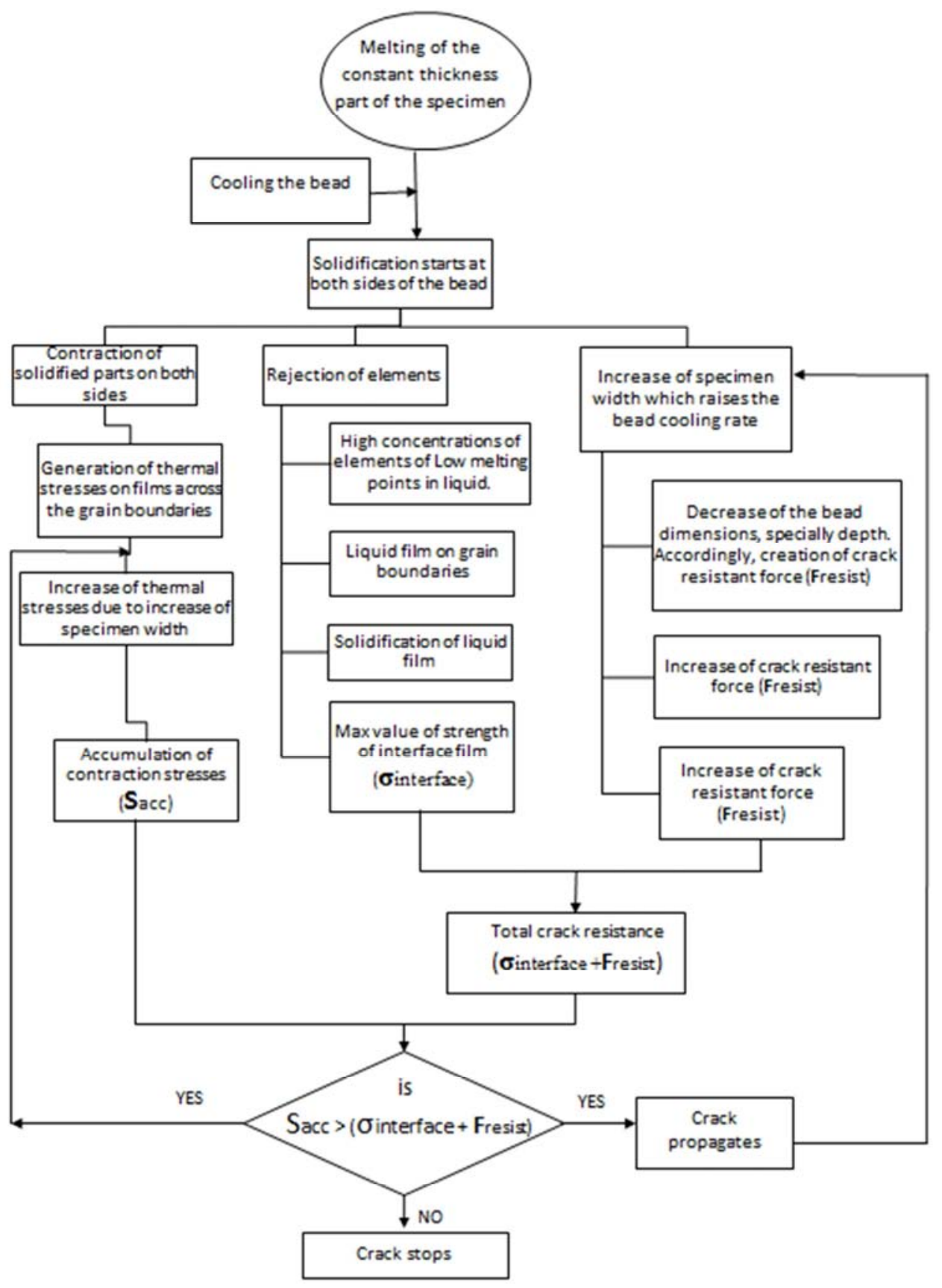

Figure 24. Flow chart of the last two stages of the proposed mechanism; "crack propagation" and "crack stop", when welding the constant thickness part of the Fan-shaped specimen. 


\subsection{Crack Ceasing}

As the welding progresses, the specimen width increases, which leads to a higher cooling rate and consequently the weld bead depth decreases. Due to decrease of the weld bead depth, a resistant force on the crack propagation will arise and increase. Therefore, the crack will cease at a critical moment when this force equals the crack opening deflection force, this occurs at a critical specimen width which depends on the welding conditions as will.

\subsection{Comparison with Previous Work}

Reviewing the previous theories established for explaining the crack occurrence, most of them dealt with the hot tears in castings, others dealt with the cracks in welding. Those who dealt with crack occurrence in welding, they separately attributed the crack occurrence either to the effect of delta ferrite, segregation of elements in weld bead, or to the thermal stresses resulted from the weld contraction. There is no definite theory joining the effects of both segregation and stresses together in explaining the occurrence of hot cracks in welding of austenitic stainless steels.

The present results produce a new approach to explain the problem of hot crack occurrence in GTAW process when applied to a fully austenitic stainless steel Fan-Shaped test specimen. The proposed mechanism is found to be in a good agreement with conclusions obtained by Lippold [43] in welding alloy 800 using the GTAW process. On the other hand there is no integral agreement between this mechanism and each of shrinkage Brittleness theory [4], and Tensile stress concept [24], which did not consider the role played by segregation.

\section{Conclusions}

This work is considered as the first trial done to formulate and propose a mechanism of hot cracks formation when welding the Fan-Shaped test specimen of austenitic stainless steel using the pulsated current GTAW process. The geometrical shape of the specimen is characterized by a first part of gradual thickness from 0 to $3 \mathrm{~mm}$ through a length of $6 \mathrm{~mm}$, the rest of the specimen has a constant thickness (3 $\mathrm{mm}$ ). The top surface of the specimen has a trapezoidal shape. The constructed mechanism of crack initiation provides a clear phenomenological interrelation between the cracking susceptibility, parameters of the welding process and material metallurgical and thermal properties. It is found that a crack always initiates at the confrontation plane of the two solidification fronts (interface) elsewhere it exists, where the accumulated contraction stresses of the solidified weld metal parts exceed the strength of this interface. Semi-quantitative distribution results obtained by line and area scanning with an EPMA show relatively large concentrations of niobium, silicon and Sulphur and/or their compounds in the crack promoting segregated phases. Due to the tapered part of the specimen, the welding starts with full depth, which helps the crack initiation as well. Hot cracks proceed inter- dendritically and tend to follow the grain boundaries of highly segregated harmful elements. It should be noted that a solidification crack once initiated, it needs not only a cracksusceptible microstructure, but also sufficient tensile stress to drive a crack open and keep it propagates.

As welding proceeds, a crack-resistive force is increasingly generated due to the reduction of the bead depth and lack of fusion as a result of the increasing cooling rate, which is direct proportional to the increasing specimen width. This resistive force impedes the crack propagation as welding going on, until the moment it exceeds the crack opening stresses at which the crack stops.

\section{Implications and Influences}

The proposed mechanism, which is described in this research, presents a first trial to explain the hot cracking formation during welding the Fan-Shaped test specimen. In addition, it contributes a new approach of compiling the roles of all affecting factors, e.g. micro-segregation, solidification, bead depth, specimen dimensions and thermal expansions.

The authors emphasize that all experiments and results included in this research are originally designed, planned and carried out to achieve it's aim.

\section{Conflict of Interest}

The authors declare that they have no competing interests.

\section{Acknowledgements}

The authors would like to thank Technical University, Berlin and Ain-Shams University, Cairo for their cooperation in producing this work.

\section{References}

[1] Pellini W. S. Strain theory of hot tearing. Foundry. November 1952, pp. 125-132.

[2] Won Y. M, Yeo T. J, Seol D. J, et al. A new criterion for internal crack formation in continuously cast steels. Met. Mater. Trans. B31, 2000, pp. 779-794.

[3] Medovar I. On the nature of weld hot cracking. Avtomatiche Svarka. Vol. 7, 1954, pp. 12-28.

[4] Borland J. C. Generalized theory of super-solidus cracking in welds and castings. BWJ. Aug, 1960, pp. 508-512.

[5] Hemsworth B, Boniszewski T, Eaton N F. Classification and definition of high temperature welding cracks in alloys. Met. Constr. Br. Weld. J. Vol. 2, 1969, pp. 2: 5-16.

[6] Shankar V, et al. Solidification cracking in austenitic stainless steel welds. Sadhana. Vol. 28, No. 3\&4, 2003, pp. 359-382.

[7] Houldcroft P. T. A simple cracking test for use with Argon-Arc welding. BWJ. Oct., 1955, pp. 471-475. 
[8] Matsuda F, Nakata K. A new Self-Restrained solidification crack susceptibility test for Electron-Beam welding of Aluminum Alloy (Fan-Shaped cracking test). Trans. Of JWRI. Vol. 11, 1982, pp. 141-143.

[9] Wang W, et al. A New Test Method for Evaluation of Solidification Cracking Susceptibility of Stainless Steel during Laser Welding. Materials. Vol. 13, 2020, p. 3178; doi: 10.3390/ma1314q3178.

[10] Brooks J. A, Lambert F. J. The effect of phosphorus, sulfur and ferrite content on weld cracking of type 309 stainless steel. WRS. May, 1978, pp. 139-143.

[11] Dixon B. Weld metal solidification cracking in ferritic steelsA review. Auster. WJ. Summer, 198, pp. 23-30.

[12] Rabensteiner G, Tosch T. The metallurgy of welding fully Austenitic CrNiMo stainless steels-An update. WJ. 1985, pp. $33-38$

[13] Borland J. C, Younger R. N. Some aspects of cracking in welded Cr-Ni Austenitic steels. BWJ. Jan, 1960, pp. 22-29.

[14] Savage W, Nippes E, Goodwin G. Effect of minor elements on hot cracking tendencies of Inconel-600. WRS. Aug., 1977, pp. 245-253.

[15] Leinachuk E, Podgaetskii B, Parfisso G. The effect of manganese on the solidification cracking resistance of weld metal. Auto. W. Vol. 30, No. 12, 1977, pp. 39-40.

[16] Tolstykh L. G. The effect of CR, Ni and Mo on the hot cracking susceptibility of steel. Welding Prod. Vol. 5, 1977, pp. $11-13$.

[17] Suutala N. Effect of solidification conditions on the solidification mode in austenitic stainless steels. Metallurgical Transactions A. Vol. 1, No. 14, 1983, pp. 191-197.

[18] Lippold J. C, Savage W. F. Solidification of austenitic stainless steel weldments: Part III-The effect of solidification behavior on hot cracking susceptibility. WRS. Dec, 1982, pp. 388-396.

[19] Abu-Aesh M. Microstructure and properties of TIG-welded joints of full-austenitic stainless steel using impulse transistor technique [Dissertation]. Egypt, Ain-Shams University, Germany, Technishe Universitat Berlin, 1988.

[20] Brooks J. A, Thompson A. W. Microstructural development and solidification cracking susceptibility of austenitic stainless steel welds. Int. Mater. Rev. Vol. 36, 1991, pp. 16-44.

[21] Hochanadel P. W, Lienert T. L, Martinez J. N, et al. Weld Solidification Cracking in 304 to $304 \mathrm{~L}$ Stainless Steel. Proceedings of the 3rd International Hot Cracking Workshop. March, 2010, Columbus, Ohio, USA, pp. 72-81.

[22] Dixon B, Phillips R, Malmgren M, et al. Cracking in the transVarestraint test, part-2: The pattern of solidification cracking. Machine Construction. March, 1984, pp. 154-160.

[23] Puzak P, Apblett W, Pellini W. Hot cracking of stainless steel weldments. WRS. Jan, 1956, pp. 9-17.

[24] Apold A. Some suggested causes of porosity and hot cracking in the metal arc welding of plain carbon steel. WR. Sept, 1952, pp. 58-66.

[25] Borland J. Suggested explanation of hot cracking in mild alloy steel welds. BWJ. July, 1960, pp. 526-540.
[26] Hull FC. Effect of Delta ferrite on the hot cracking of stainless steel. WRS. Sept, 1967, pp. 399-409.

[27] Savage W, Dickinson W. Electron Microanalysis of backfilled hot cracks in Inconel600. WRS. Nov, 1972, pp. 555-561.

[28] Arata Y, Matsuda F, Nakagawa H, et al. Solidification cracking susceptibility in weld metals of fully austenitic stainless steels (Report III). Trans. of JWRI. Nov, 1977, pp. 37-46.

[29] Matsuda F, Nakagawa H, Sorada K. Dynamic observation of solidification and solidification cracking during welding with optical Microscope (I). Trans. of JWRI. Vol. 11, No. 2, 1982, pp. 67-77.

[30] Abu-Aesh M, Taha M, El-Sabbagh AS, et al. Hot-cracking susceptibility of fully austenitic stainless steel using pulsedcurrent GTAW process. Engineering Reports, John Wiley. Sept, 2020, pp. 1-13.

[31] Ripple P. Wechslbeziehung zwischen statichem und dynamischem stromquellenverhalten und proze Bablauf beim lichtbogenschweiBen [Interrelationship between static and dynamic power source behavior and process sequence in arc welding] [Dissertation]. Berlin, Technische Universitat; 1983, pp. 21-45.

[32] Matyash V. I, Pakharenko V. A. Special features of weld pool Soliditication during pulsed arc welding with electromagnetic action. Auto. W. Vol. 9, Sept, 1983, pp. 54-55.

[33] Matsuda F, Nakata K, Harada S. Moving characteristics of weld edges during solidification in relation to solidification cracking in GTA Weld of Aluminum alloy thin sheet. Trans. of JWRI. Vol. 9, No. 2, 1980, pp. 225-235.

[34] Jialie R, Anli L, Fushen C, et al. Deformation and crack formation in weld during its solidification. Int. Conf. WI of CMES, Hangzhou-China. Sept, 1984, pp. 3: IX. 3.1-IX. 3.6.

[35] El-Salamoni M. A, El-Sawy A, El-Hebary M, et al. Assessment of steel weld metal solidification cracking. Metallurgy Suplement of AIME. (AB5-13), pp. 1-14.

[36] Fredriks H, Van der Toorn L. J. Hot cracking in Austenitic Stainless Steel Weld deposits. BWJ. Vol. 15, No. 4, Apr 1968, pp. 178-182.

[37] Kujanpaa V. P. Weld discontinuities in austenitic stainless steel sheet- effect of impurities and solidification mode. WRS. Dec, 1984, pp. 369-375.

[38] Arata Y, Matsuda F, Nakagawa H, et al. Solidification crack susceptibility in weld metals of fully austenitic stainless steels (Report IV). Trans. of JWRI. Oct, 1978, pp. 21-240.

[39] Matsuda F, Katayama S, Arata Y. Solidification crack susceptibility in weld metals of fully austenitic stainless steels (Report V). Trans. of JWRI. Oct, 1981, pp. 73-84.

[40] Mishler H, Rippel P. Studies of hot cracking in high strength weld metals. WRS. Jan, 1961, pp. 1-7.

[41] Homma H, Mori N, Shinmyo K. A mechanism of high temperature cracking in steel weld metals. WRS. Jan, 1979, pp. 277-282.

[42] Ogawa T, Tsunetomi E. Hot cracking susceptibility of austenitic stainless steels. WRS. March, 1982, pp. 82-93.

[43] Lippold J. C. An investigation of weld cracking in Alloy 800. WRS. March, 1984, pp. 91-103. 
[44] Koch J, Hill K. Failure analysis of type-330 welds by SEM. WRS. Aug, 1980, pp. 242-244.

[45] Lundin C. D, Chou C. P. D. Bulletin of Welding Research Council. No. (289), Nov, 1983, pp. 1-80.

[46] Wedgery D. J. Effects of Sulphur and Phosphorus on weld metal solidification cracking. MC and BWJ. Aug, 1970, pp. 333-338.

[47] Matsuda F, Nadagawa H, Katayama S, et al. Solidification crack susceptibility in weld metals of fully austenitic stainless steels (Report VII). Trans of JWRI. Sept, 1982, pp. 79-85.

[48] Arata Y, Matsuda F, Katayama S. Solidification crack susceptibility in weld metals of fully austenitic stainless steels (Report II). Trans of JWRI. Sept, 1982, pp. 105-116.

[49] Jones P. W. An Investigation of hot cracking in Low-Alloy steel welds. BWJ. June, 1959, pp. 282-290. Wilkinson F, Cottrell C, Huxley H. Calculating hot cracking resistance of high tensile alloy steel. BWJ. Dec, 1958, pp. 557-564.

[50] Honeycombe R. W. Steels microstructure and properties. Edward Arnold publisher Ltd. London. Oct, 1981 pp. 211-244.

[51] Folkhardt E. Metallurgie der schweiBungen nichtrostender stahle [Metallurgy of stainless steel weldments]. Wien, Springer-Verlag. 1984, pp. 32-36.

[52] Ploshikhin V, Prihodovsky A, Ilin A. Experimental investigation of the hot cracking mechanism in welds on the microscopic scale. Frontiers of Materials Science. Vol. 5, June, 2011, pp. 135-146.

[53] Manitsas D, Andersson J. Hot Cracking Mechanisms in Welding Metallurgy: A Review of Theoretical Approaches. MATEC Web of Conferences-188, 03018, 2018; ICEAF-V18. 